\title{
Socio-hydrologic modeling to understand and mediate the competition for water between agriculture development and environmental health: Murrumbidgee River basin, Australia
}

\author{
T. H. M. van Emmerik ${ }^{1}$, Z. Li ${ }^{2}$, M. Sivapalan ${ }^{2,3}$, S. Pande ${ }^{1}$, J. Kandasamy ${ }^{4}$, H. H. G. Savenije ${ }^{1}$, A. Chanan ${ }^{5}$, and \\ S. Vigneswaran ${ }^{4}$ \\ ${ }^{1}$ Department of Water Management, Faculty of Civil Engineering and Geosciences, Delft University of Technology, \\ Delft, the Netherlands \\ ${ }^{2}$ Department of Civil and Environmental Engineering, University of Illinois at Urbana-Champaign, \\ Hydrosystems Laboratory, Urbana, USA \\ ${ }^{3}$ Department of Geography and Geographic Information Science, University of Illinois at Urbana-Champaign, \\ Computer Applications Building, Urbana, USA \\ ${ }^{4}$ School of Civil and Environmental Engineering, University of Technology Sydney, Broadway, Sydney, NSW, Australia \\ ${ }^{5}$ State Water Corporation of New South Wales, Sydney, Australia
}

Correspondence to: T. H. M. van Emmerik (t.h.m.vanemmerik@ tudelft.nl)

Received: 28 February 2014 - Published in Hydrol. Earth Syst. Sci. Discuss.: 24 March 2014

Revised: 18 September 2014 - Accepted: 22 September 2014 - Published: 29 October 2014

\begin{abstract}
Competition for water between humans and ecosystems is set to become a flash point in the coming decades in many parts of the world. An entirely new and comprehensive quantitative framework is needed to establish a holistic understanding of that competition, thereby enabling the development of effective mediation strategies. This paper presents a modeling study centered on the Murrumbidgee River basin (MRB). The MRB has witnessed a unique system dynamics over the last 100 years as a result of interactions between patterns of water management and climate driven hydrological variability. Data analysis has revealed a pendulum swing between agricultural development and restoration of environmental health and ecosystem services over different stages of basin-scale water resource development. A parsimonious, stylized, quasi-distributed coupled socio-hydrologic system model that simulates the twoway coupling between human and hydrological systems of the MRB is used to mimic and explain dominant features of the pendulum swing. The model consists of coupled nonlinear ordinary differential equations that describe the interaction between five state variables that govern the co-evolution: reservoir storage, irrigated area, human population, ecosystem health, and environmental awareness. The model sim-
\end{abstract}

ulations track the propagation of the external climatic and socio-economic drivers through this coupled, complex system to the emergence of the pendulum swing. The model results point to a competition between human "productive" and environmental "restorative" forces that underpin the pendulum swing. Both the forces are endogenous, i.e., generated by the system dynamics in response to external drivers and mediated by humans through technology change and environmental awareness, respectively. Sensitivity analysis carried out with the model further reveals that socio-hydrologic modeling can be used as a tool to explain or gain insight into observed co-evolutionary dynamics of diverse human-water coupled systems. This paper therefore contributes to the ultimate development of a generic modeling framework that can be applied to human-water coupled systems in different climatic and socio-economic settings.

\section{Introduction}

The world is facing severe water management challenges, in the context of population growth, degradation of poorly distributed resources and the considerable uncertainties posed 
by the effects of climate change (Falkenmark and Lannerstad, 2005; Wagener et al., 2010). The rapid rates of change that the water cycle and the environment are likely to experience as a result of increasing human impacts (e.g., anthropogenic climate change, land use and land cover changes) require prediction and management frameworks that capture the coupling between, and feedbacks across, engineered, natural, and social systems (Sivapalan, 2011; Savenije et al., 2014). In many parts of the world such as Australia, climate change and the need to provide water, food and other amenities for a growing population have posed major challenges for water management (UNEP, 2007). Increased water extraction for agriculture in many parts of Australia has resulted in mounting pressure on, and degradation of, riparian environments. Planned cutbacks in water allocation for irrigation to alleviate environmental degradation have resulted in a sharper focus on the economic livelihood of rural Australia. This is clearly evidenced by the heated debate over water use in the Murray-Darling basin in eastern Australia, where competition for water resources between humans and ecosystems has come to the fore in recent times ( $\mathrm{ABC}$, 2010; Roderick, 2011). Not surprisingly then, there is a critical need for new theoretical and quantitative frameworks (Ostrom, 2009; Gleick and Palaniappan, 2010; Grafton et al., 2013) to understand and mediate the competition for water between humans and the environment through generating new understanding of how they coexist and interact.

Of the many interacting processes in the earth system, human processes are now the dominant drivers of change in water, nutrient, and energy cycles, and in landscape evolution (Vitousek et al., 1997; Crutzen and Stoemer, 2000; Röckstrom et al., 2009; Vörösmarty et al., 2010; Zalasiewicz et al., 2010). Rapid population growth and increased appropriation of freshwater supplies means that hydrologic and human systems are now intrinsically coupled. Human settlement patterns, economic production and demographics are related to the availability of freshwater services as growing human populations alter natural water systems to suit social needs. Human management of the water cycle results in enormous complexity in coupled human-hydrological systems, spanning both physical infrastructure and the economic, policy and legal frameworks governing water availability, use and pricing. Explicitly confronting hydrological predictions in the context of human behavior poses challenges towards quantification of hydrological systems in terms that are meaningful within economic or policy frameworks.

With the continued expansion of the human footprint, not only are landscape properties changing, but there is also potential for new forms of hydrological behavior to arise due to exceedance of known or previously unknown thresholds (Zehe and Sivapalan, 2009; Kumar, 2011). Hydrological predictions must therefore be based on explicit accounting of both changes in landscape structure as well as the possibility for new dynamics that might emerge from such humanenvironment interactions (Kallis, 2007, 2010). Patterns of

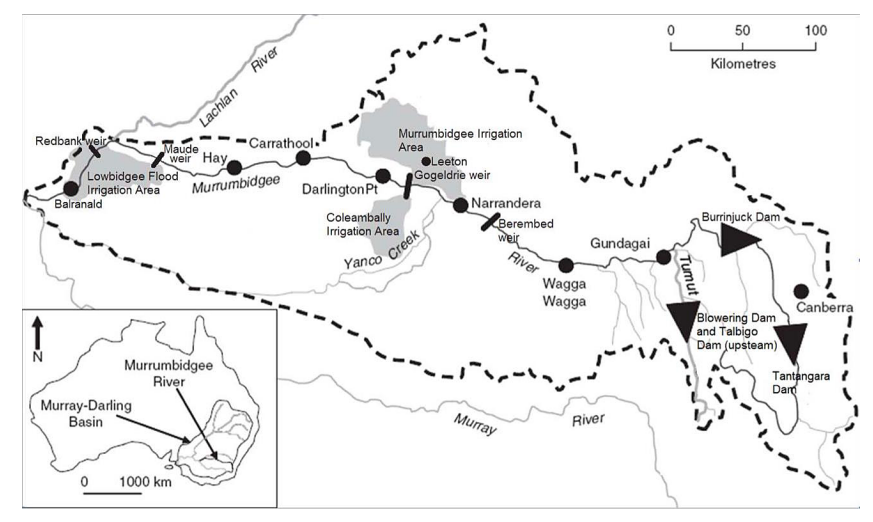

Figure 1. Location of the Murrumbidgee basin within the MurrayDarling river basin (Kandasamy et al., 2014).

human modification in the landscape are themselves phenomena to be studied and interpreted, so we can more deeply understand the consequences of human intervention in the past, and better plan engineered responses to future challenges. Wagener et al. (2010) have called for a new paradigm for hydrologic science that includes human-induced changes as integral to the overall hydrologic system. To address these challenges Sivapalan et al. $(2012,2014)$ have proposed the sub-field of socio-hydrology with "a focus on the understanding, interpretation and prediction of the flows and stocks in the human-modified water cycle at multiple scales, with explicit inclusion of the two-way feedbacks between human and water systems".

\section{Murrumbidgee (Australia) case study}

This paper presents a socio-hydrologic modeling study centered on the Murrumbidgee River basin (MRB) (Fig. 1), a sub-basin of the much larger Murray-Darling basin. The Murray-Darling basin has recently witnessed heated debate over water use as a result of heavy competition for water resources between humans and ecosystems (Roderick, 2011). Data analysis carried out by Kandasamy et al. (2014) using data from the Murrumbidgee River basin has revealed a "pendulum swing" between an exclusive focus in the initial stages on water extraction for food production, and later efforts to mitigate and reverse the consequent degradation of the riparian environment. The basin witnessed a rapid rise in population in the early decades, amid increasing concerns of salinity and declining ecosystem services. It was able to sustain the growth in population and agricultural production by first increasing reservoir storage capacities and then through investments in infrastructure and technologies that helped to control soil salinity and algal blooms, such as efficient irrigation systems, barrages and upgraded sewage treatment plants. Yet, in the end, it was unable to curb the 
eventual decline in population and in agricultural production that began around 1990 .

The decline in the water available for the environment and its ultimate degradation as a consequence led to the rise of the notion of the "environmental consumer" in the basin (Kandasamy et al., 2014). This implied a change in the preferences of the population within the basin and the society at large towards a better environment. The system reached the stage whereby inhabitants of the MRB, and especially in the wider society, were no longer solely driven by the income that agriculture generated if it came at the cost of environmental degradation. They reached the point where they were willing to give up water consumption to achieve improved environment quality and to satisfy environmental demands. Such a change in the values and norms of individuals within the basin and in the wider society resulted in a different dynamics between agricultural production and environment quality (Chen and Li, 2011; Sivapalan et al., 2014). The changing values and norms, via changes in the dynamics of human consumption and environment quality, fed back to changes in the delivery of ecosystem services. Overall, the rise and the fall of population and crop production led to a spatio-temporal pendulum swing that is best illustrated by the area planted with rice within the basin (see Fig. 4c in Kandasamy et al., 2014; see also Sivapalan et al., 2012).

With this paper, we aim to demonstrate that sociohydrologic modeling can be used as a useful tool to study and explain observed co-evolutionary dynamics of coupled human-water systems. This paper thus represents an attempt to explore through numerical simulation the main drivers of the "pendulum swing" observed in the Murrumbidgee. We present a stylized, quasi-distributed and coupled sociohydrologic system model that explicitly includes the twoway coupling between humans and nature (e.g., the hydrologic system), including the evolution of human values/norms relating to water and the environment. We use it to mimic broad features of the observed pendulum swing described by Kandasamy et al. (2014), and in so doing generate insights into the dominant drivers (both exogenous and endogenous) of the trajectory of co-evolution of the coupled human-water system, and in this way develop a broad theoretical framework that may potentially be transferable to other systems in different climatic and socio-economic settings. This modeling work also contributes to efforts aimed at developing generic model frameworks for coupled sociohydrologic systems that involve a competition for water between humans and the environment (Elshafei et al., 2014).

\section{Model description}

Kelly et al. (2013) described a wide class of approaches to modeling coupled human and environmental systems and suggested a framework for choosing an approach that is suitable for the problem at hand. In the area of socio-hydrology, there have been several recent efforts at developing simple conceptual (or stylized) models of coupled human-water systems. For example, Di Baldassarre et al. (2013a, b) developed a simple, dynamic human-flood model to represent the interactions and feedbacks between hydrological and social processes in the context of urban flooding. Liu et al. (2014) likewise proposed a coupled human-water system model to mimic the competition for water between humans and the environment in the Tarim River basin in western China. Srinivasan (2013) presented a coupled humanwater system model in the context of urban water supplies in the city of Chennai, India. These models belong to a class of system dynamics models with a rich history of modeling the coupled dynamics of human populations, economic growth and general resource availability at a variety of spatio-temporal scales (Forrester, 1971; Cuypers and Rademaker, 1974; Vörösmarty et al., 2000; Turner, 2008; Davies and Simonovic, 2011). Alternatively, although with some subtle differences, there have been efforts at developing coupled conceptual water and economic system models (also known as hydro-economic models) in the context of basin-scale water allocation (Pande et al., 2011), groundwater management (Pulido-Velazquez et al., 2006), and agricultural water management (Knapp et al., 2003; Maneta et al., 2009). Another layer of complexity can be added to these approaches by invoking the principles that underpin how individuals organize themselves (Greif and Laitin, 2004; Pande and Ertsen, 2014), accounting for changing values and norms (Sivapalan et al., 2014), or allowing for changing structure of coupled human water systems and how it affects the resulting dynamics (Kallis, 2007, 2010). The degree of belief in the coupled dynamics simulated by these approaches is enhanced by also explicitly modeling the feedbacks between economic growth, population size and also technology change, where applicable (Eicher, 1996; Pande et al., 2014). The model presented in this paper goes some ways towards combining the strengths of these previous attempts at sociohydrological modeling.

Before we present the details of the model of the Murrumbidgee basin system, however, it is pertinent to present the motivation and scope of the modeling framework being presented. At this early stage, simplified equations are used to model the main drivers in the catchment, i.e., hydrology, irrigation, ecology and population size. As discussed later, the governing equations have "intuitive" basis in the relevant literature and their parameters are calibrated to mimic the data trends. It is acknowledged up front that the predicted timings and magnitudes will not exactly match actual occurrences in the past, yet the simulated trends or patterns are consistent with those observed. This paper aims to show that a socio-hydrologic modeling framework might be used to study complex coupled human-water systems. The main goal of the model development is therefore to demonstrate that despite complex interactions, the dominant patterns can be reproduced. Yet another objective of model development 

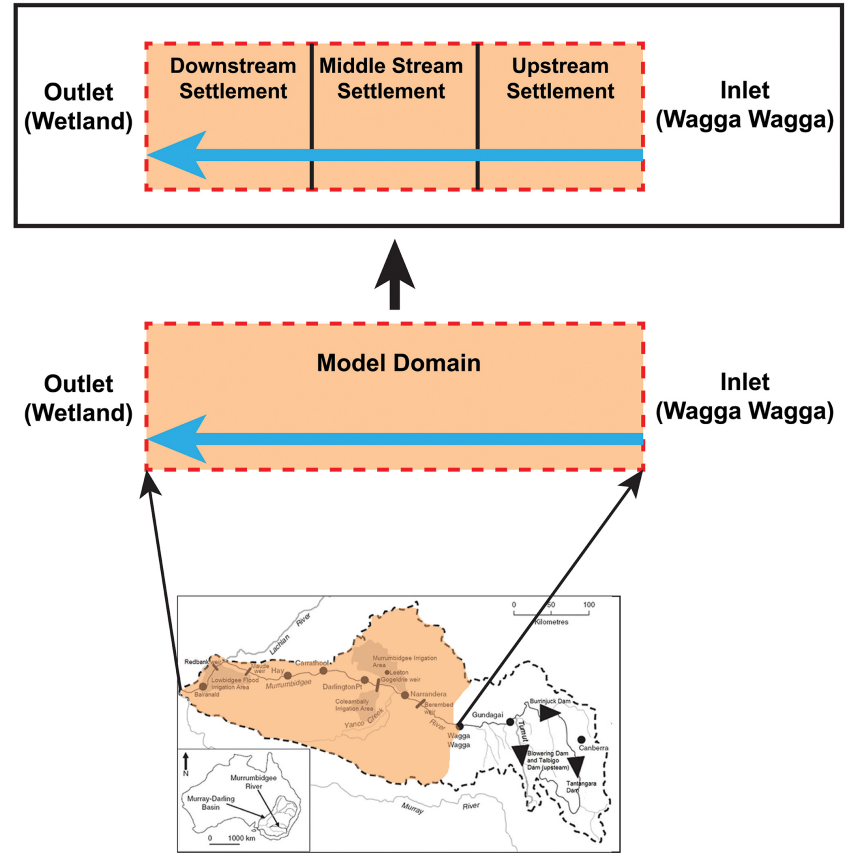

Figure 2. Model domain and the discretization into three settlements (downstream, middle stream and upstream).

is to trigger further study of the complexities of human water interactions, especially the governing equations and associated constitutive relationships. This will expand the possibility of implementing socio-hydrological models, guide future decisions on catchment water management, and communicate to the practicing engineer/basin manager the potential and value of socio-hydrology.

\subsection{Model domain}

The MRB is located in southeastern Australia, has a drainage area of $85000 \mathrm{~km}^{2}$, and forms part of the iconic MurrayDarling basin (Fig. 1). The headwaters of the Murrumbidgee River are located in the Snowy Mountains in the east, from where the river flows west towards the outlet, which is at the confluence with the Murray River. Much of the agricultural activity happens downstream (i.e., west) of Wagga Wagga. For this reason, the study domain is restricted to the area of the MRB west of Wagga Wagga (as shown in Fig. 2, with drainage area of $60000 \mathrm{~km}^{2}$ ). The measured discharge at Wagga Wagga is therefore the main water inflow to the system, supplemented by rain that falls over the study domain. In order to mimic internal relocation of humans and associated agricultural activity, the model domain on the MRB is notionally divided into three equal sub-regions or settlements denoted here as upstream, middle stream and downstream (Fig. 2). The aim here is merely to demonstrate the working of the model and not to correlate well with observed irrigation areas (see Fig. 1). The geomorphic properties are as- sumed to be the same for the three settlements (i.e., they have the same catchment area and area available for irrigation).

\subsection{Governing equations}

The model consists of five coupled nonlinear ordinary differential equations that describe the interaction between state variables that govern the co-evolution: reservoir storage (hydrology), irrigated area, size of the human population, a measure of ecosystem health and an indicator of changing environmental awareness within society.

The hydrology equation represents water storage, irrigation water use and river discharge variations from a water balance perspective. The irrigation equation simulates the dynamics of the irrigation area per capita subject to water availability, technology change and environmental degradation. The population equation tracks the dynamics of population size through internal growth, migration from outside, and internal (both upstream and downstream) relocation. The ecology equation simulates water storage in notional riparian wetlands located downstream of the study region (i.e., downstream of the downstream section) that are episodically recharged by river flow during high flow events. The environmental awareness equation tracks the dynamics of community sensitivity to the degradation of ecosystem health, here exclusively focused on the health of riparian wetlands.

Explicit inter-connections are built in between these five principal equations through assumed constitutive relationships that allow for the relevant feedback mechanisms (both positive and negative) to operate. The first three equations (irrigation area, population size, reservoir storage) are developed for each sub-region separately (upstream, middle stream, downstream). Humans are allowed to relocate internally between these sub-regions (in both directions), water is exchanged only in the downstream direction, and obviously no exchange of irrigation area is allowed. The last two equations (ecosystem health and environmental awareness) are applicable to the wetlands only, and are therefore systemwide equations. Details of each of the five model components and their interconnections are presented next. Note that in this study, the constitutive relationships that are used to link the governing equations are not prescribed; rather, both their functional forms and associated parameter values are obtained by calibration. The functional forms and parameters were adjusted based on expert knowledge, combined with calibration, and was governed by two contrasting modeling demands. The first is the need for realistic relationships between variables. The second is the aim to keep the formulation as simple as possible. Details about these are therefore only presented as part of the results section.

\subsubsection{Irrigation equation}

In this study, irrigation activity is expressed in terms of irrigated area per capita. This helps to separate the effect of 
population size, the dynamics of which is treated separately (see later). The governing equation for irrigation is given by

$$
\frac{\mathrm{d} a_{i}}{\mathrm{~d} t}=\alpha_{\tau}(T)+\alpha_{\mathrm{S}}\left(S_{i}\right)+\alpha_{\mathrm{E}}(E)
$$

where $a_{i}$ is irrigated area per capita, and $i$ refers to the subregion. In Eq. (1), the dynamics of $a_{i}$ is governed by three growth rates, expressed by three constitutive relationships: $\alpha_{\tau}(T)$ (function of technology, $T$ ), $\alpha_{\mathrm{s}}(S)$ (function of water storage, $S$ ), $\alpha_{\mathrm{E}}(E)$ (function of community environmental awareness, $E$ ).

In this paper, we consider technology, $T$, very broadly, and use it to embrace a whole gamut of advances, such as mechanization, advanced irrigation practices (e.g., drip irrigation), planting strategies to maximize water use, and plant breeding to increase crop yield (see, for example, Hayami and Ruttan (1970) for a discussion of the two broad types of agricultural technology: "mechanical" and "biological and chemical"). All of these contribute to higher $a_{i}$, and are reflected in $\alpha_{\tau}(T)$. Secondly, $a_{i}$ is also governed by the amount of water available for irrigation. Availability of water (e.g., storage in the reservoir), provides confidence to farmers deciding to settle, invest and expand. Equation (1) captures this dependence in terms of constitutive relationship between the growth rate, $\alpha_{\mathrm{s}}$, and reservoir storage $(S)$ on the annual timescale. On the opposite side, increasing awareness of environmental degradation may motivate some farmers to voluntarily forego a part of their land during periods of drought for the sake of environmental protection. The growth rate, $\alpha_{\mathrm{E}}$ (less than zero), expressed as a function of environmental awareness, $E$, is used to capture the negative feedback in response to environmental degradation. Clearly, the dynamics of $a_{i}$ is geared to the dynamics of reservoir storage, $S$, and environmental awareness, $E$. These dynamics are explicitly captured through associated differential equations, which are described next. Technology, $T$, changes with time too and here it is assumed to increase with time varying wealth, the details of which are presented later.

\subsubsection{Population equation}

The model simulations begin with an initially small population located in the downstream settlement only (denoted as 1, Fig. 2), and zero populations in the middle stream and upstream settlements (denoted as 2 and 3, respectively). Subsequent change in population size can be due to three factors: natural growth (i.e., birth-death), migration (from outside), and internal relocation (up or down migration between settlements). For simplicity, the model assumes that migration to and from the outside is only to the downstream settlement. This assumption is based on results from Kandasamy et al. (2014), where this mechanism was observed in the early phase of settlement in the MRB. In addition, a model design with migration to and from the outside to the downstream, middle stream and upstream settlements did not yield better results and only increased model complexity. This means that the middle stream and upstream settlements populate or depopulate through internal relocation and subsequent internal growth. The governing equation for population dynamics for each of the settlements is given by:

$$
\begin{aligned}
\frac{\mathrm{d} N_{1}}{\mathrm{~d} t} & =N_{1}\left\{\psi_{\mathrm{n}}+\psi_{\mathrm{m}}\left(\varphi_{1}\right)\right\}+N_{2} \psi_{\mathrm{r}_{21}}-N_{1} \psi_{\mathrm{r}_{12}} \\
\frac{\mathrm{d} N_{2}}{\mathrm{~d} t} & =N_{2} \psi_{\mathrm{n}}+N_{1} \psi_{\mathrm{r}_{12}}+N_{3} \psi_{\mathrm{r}_{32}}-N_{2} \psi_{\mathrm{r}_{23}} \\
\frac{\mathrm{d} N_{3}}{\mathrm{~d} t} & =N_{3} \psi_{\mathrm{n}}+N_{2} \psi_{\mathrm{r}_{23}}-N_{3} \psi_{\mathrm{r}_{32}}
\end{aligned}
$$

where $\psi_{\mathrm{n}}, \psi_{\mathrm{m}}$ and $\psi_{\mathrm{r}}$ are the population growth rates: $\psi_{\mathrm{n}}$ is natural growth rate (assumed constant), $\psi_{\mathrm{m}}$, is growth rate through migration from outside, $\psi_{\mathrm{r}_{i j}}$ is rate of growth or loss through internal relocation. In Eq. (2a), $N_{2} \psi_{\mathrm{r}_{21}}$ refers to growth through relocation from settlements 2 to 1 , whereas the term $N_{1} \psi_{\mathrm{r}_{12}}$ refers to loss through relocation from settlements 1 to 2 .

The model assumes that people either move into an area or leave on the basis of a relative attractiveness level, defined as $\varphi$. In Eq. (2), the external migration rate, $\psi_{\mathrm{m}}$, into settlement 1 is assumed to be a nonlinear function of the level of attractiveness, $\varphi_{1}$ (see Table 3 for details of the associated (calibrated) constitutive relationship). The level of attractiveness of any given region $i$ is expressed in terms of the per capita irrigation potential

$\varphi_{i}=\left(a_{i}^{\max }-a_{i}\right)$,

which is the difference between the potential (maximum possible) area available for irrigation and the actual (present) area under irrigation, on a per capita basis. Broadly we hypothesize that people migrate to the basin, and/or relocate within the basin, in order to maximize their (per capita) income potential (see, e.g., Fedotov et al., 2008 for a similar formulation). However, for simplicity and as a first step, we have assumed that irrigation potential (Eq. 3) can serve as a surrogate for the income potential. In reality, however, income potential can also be impacted by water availability, the state of the environment, and several other factors. There is therefore considerable room for improvement of this formulation in the future, especially as more data become available and our understanding of human motivations improves. The idea that people migrate to maximize their economic profit is based on microeconomic fundamentals. The MRB is an agriculture dominated area, where throughout the 20th century population change and agricultural development occurred side by side (Kandasamy et al., 2014). Therefore it is a reasonable assumption that the migration of people is determined by irrigation potential (economic gains) and environmental awareness (economic losses).

In Eq. (2), the relocation rate, $\psi_{\mathrm{r}_{i j}}$, between two different settlements within the basin, $i$ and $j$, is assumed to be, to first order, a function of the difference in the levels of attractiveness between the two. The difference in attractiveness, 

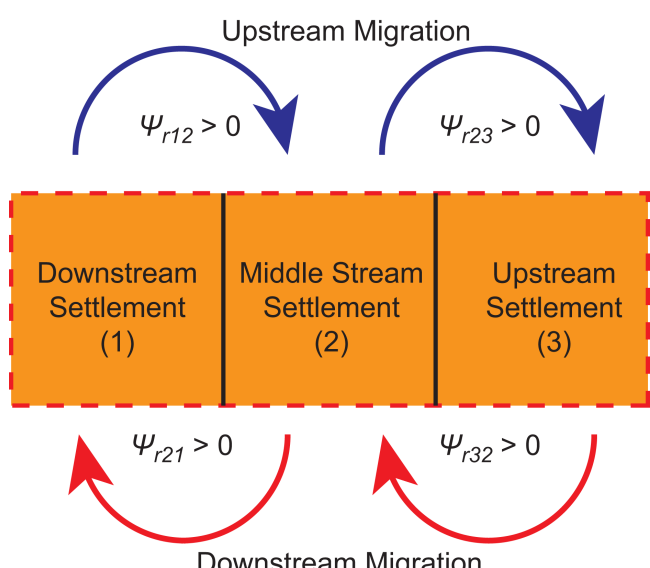

Figure 3. Schematic diagram describing the framework adopted in the model for internal relocation of humans between the three settlements (see Eqs. 2-4).

$\left(\varphi_{j}-\varphi_{i}\right)$, can be seen as a gradient that drives the relocation. In this paper, in addition, we make a further correction to reflect possible human desire to help mitigate the resulting environmental degradation. The relocation rate, $\psi_{\mathrm{r}_{i j}}$, is then governed by a combination of the attractiveness gradient and environmental awareness, $E$. The resulting equation for $\psi_{\mathrm{r}_{i j}}$ is given by:

$\psi_{\mathrm{r}_{i j}}=r\left(\varphi_{j}-\varphi_{i}\right)+c E$

where $r$ and $c$ are constants. Figure 3 conceptualizes the model formulation for the relocation of people: when $\psi_{\mathrm{r}_{i j}}>$ 0 the movement is from settlement $i$ to $j$, when $\psi_{\mathrm{r}_{i j}}<0$ the movement is from $j$ to $i$. Equation (3) thus creates a relocation dynamics between the three downstream, middle stream and upstream settlements that emerges endogenously with the growth of irrigated areas, population size and environmental awareness.

The inclusion of the environmental awareness in Eq. (4) is to accommodate a curb on the expansion of irrigated area and return part of the irrigated area back to nature. Such actions limit local consumption of water, and allows for more water to recharge the wetlands downstream. In this model, the inclusion of environmental awareness has the net effect of shifting people downstream. When the sign of $c E$ is positive, and $\varphi_{j}-\varphi_{i}$ is downstream directed, environmental awareness accelerates downstream relocation; and when the sign of $c E$ is negative, and $\varphi_{j}-\varphi_{i}$ is upstream-directed, upstream relocation decelerates.

\subsubsection{Hydrology equation}

The hydrology equation, essentially a water balance equation, tracks the dynamics of water stored within any one settlement $(i=1,2,3)$ on a daily time step. The net inputs to a settlement are inflows at its upstream end (i.e., measured in- flows at Wagga Wagga for the upstream settlement, or modelsimulated inter-settlement flows in the case of the middle stream and downstream settlements), plus the runoff generated within the settlement from rainfall. Net outputs are outflows/overflows to the settlement located downstream, and the amount of water extracted for irrigation. At the beginning of simulations (circa 1910), there is no reservoir storage. The daily water balance equation for settlement $i$ is given by:

$$
\begin{aligned}
\frac{\mathrm{d} S_{i}}{\mathrm{~d} t} & =Q_{i}^{\mathrm{in}}+A_{i}^{\mathrm{c}} \beta p_{i}-\max \left\{\left(\gamma_{\mathrm{s}}(T)-(1-\beta) p_{i} N_{i} a_{i}\right), 0\right\} \\
& -Q_{i}^{\text {out }}
\end{aligned}
$$

where $S_{i}$ is net storage within the settlement, including reservoir storage (once it is constructed), $Q_{i}^{\text {in }}$ is inflow at the upstream end, and $Q_{i}^{\text {out }}$ is outflow to the settlement at the downstream end. The second term on the RHS (right-hand side) of Eq. (5) is the rate of runoff generated internal to the settlement, expressed as a product of the "physical" catchment area $A_{i}^{\mathrm{c}}$, average rainfall intensity $p_{i}$, and a runoff coefficient $\beta$, which is assumed to be constant here for simplicity. The third term is net water extraction for irrigation, after accounting for rainfall. Here $N_{i} a_{i}$ is total irrigated area, and $\gamma_{\mathrm{s}}(T)$ is crop water demand per unit area, and their product is the net demand for water. During rainfall events, since crops can directly access water from rainfall, water extraction is the demand not met by the net amount of rainfall over the irrigated area. When rainfall is more than enough to satisfy the irrigation demand, water extraction is set to zero. Crop water demand per unit area, $\gamma_{\mathrm{s}}(T)$, changes with time through technological advances such as crop breeding. For this reason, $\gamma_{\mathrm{s}}(T)$ is estimated as a function of technology, $T$ (see later for details).

Early in the simulations, we assume that there are no reservoirs and temporary detention storage in the river is the only storage in the system. Water is extracted directly from the river, and during this early period excess water simply passes through to the downstream. However, the model is conditioned such that on the basis of the trigger of a persistent deficit in the water available over many years to meet irrigation demand, a reservoir is introduced endogenously to mitigate that deficit. We define "water shortage days" $(\omega)$ as the number of days in a year when the sum of storage in the reservoirs and river flow is less than the irrigation demand (e.g., during a period of drought). These days are monitored over the years to quantify "water sufficiency". The decision to construct a reservoir and the timing of that construction are both linked to the number of "water shortage days". Reservoir construction is triggered when the mean "water shortage days", $\omega$, over five years exceeds a specified drought threshold $\delta$ (days). Once the reservoir is constructed, the threshold $\delta$ is doubled (but to a value not larger than 365 days), thereby modeling an evolving tolerance for drought. The size of the reservoir $\Omega$ at each stage of construction notionally follows user demand. We assume that $\Omega$ is linearly related to irrigation demand, given by $\Omega=10 \gamma_{\mathrm{s}} N_{i} a_{i}$. When river flow is 
not enough to satisfy the irrigation water demand, reservoir storage (if already built) releases water to meet the unmet demand. The amount of water released is the difference between water demand and river flow. In the MRB, agriculture dominates, and therefore we neglect household water use.

\subsubsection{Ecology equation}

In this paper, ecology refers to the functioning of the chain of riparian wetlands, which are episodically recharged when river flow exceeds a prescribed threshold released from the downstream settlement $(i=1)$. The wetlands are assumed to exist notionally only, and are located downstream of the downstream settlement (i.e., outside of the basin; for example, they may refer notionally to the Lowbidgee wetlands, which are the largest wetlands located within the MRB). The ecology governing equation is the water balance equation of these wetlands, which receive water episodically through overflows of the river, and then over a longer time lose the water through a combination of leakage and evaporation. Both leakage and evaporative losses are assumed to be proportional to the storage. This water balance equation is thus given by

$$
\frac{\mathrm{d} W}{\mathrm{~d} t}=\max \left(0, Q_{1}^{\text {out }}-\mu\right)-k W
$$

where $W$ is the storage in the wetlands, $Q_{1}^{\text {out }}$ is the river discharge reaching the wetlands (outflow from the downstream section), $\mu$ is the recharge/overflow threshold above which the wetland is recharged, and $\kappa$ is a coefficient representing the combination of evaporation and leakage loss.

\subsubsection{Environmental awareness equation}

The wetland storage simulated by the ecology equation (Eq. 6) is used as a predictor of ecosystem health. The state of ecosystem health is assumed to impact human behavior with respect to irrigation area expansion and water extraction in a way that mitigates any environmental degradation and thus helps to maintain or improve ecosystem health. In the model, such human feedbacks are channeled through a dynamic state variable called environmental awareness, $E$.

It is assumed that environmental degradation takes place whenever wetland storage, $W$, falls below a threshold, $W_{\mathrm{d}}$. It is only when this happens that environmental degradation is recognized by the community, and the longer it persists, the longer the environmental awareness, $E$, accumulates. On the other hand, whenever $W$ is higher than $W_{\mathrm{d}}$ for the entire year, then we allow the accumulated $E$ to deplete. In other words, environmental awareness, $E$, is akin to a memory bank that accumulates during times when the environment degrades, and depletes during relatively healthier times.

Because of the episodic nature of these exceedances, we define $n$ as the number of days in a year during which $W$ is below the threshold. Clearly $n$ is connected to the wetland storage dynamics (Eq. 6), and therefore represents the coupling of environmental awareness to the ecology equation. When $n$ is positive, then $E$ accumulates, whereas when $n$ is zero then $E$ is allowed to deplete. The temporal dynamics of $E$ is then given by the following differential equation:

$$
\frac{\mathrm{d} E}{\mathrm{~d} t}=\varepsilon(n)
$$

where $\varepsilon(n)$ is the rate of accumulation/depletion of environmental awareness. The functional form of $\varepsilon(n)$ is calibrated so as to mimic the observed pendulum swing (the calibrated expression for $\varepsilon(n)$ is presented in Table 3 ). In reality its exact formulation will rely on ecological considerations, which is beyond the scope of this study. We also highlight our assumption in this paper that environmental awareness is solely driven by the ecological well-being, a variable that is local to the basin. Macro-scale variables, such as regional or national politics and economy and climate, may play a role in determining the dynamics of environmental awareness as indicated in the general framework proposed by Elshafei et al. (2014), but have been ignored here.

\subsection{Model coupling: cross-system feedbacks}

The socio-hydrologic model presented above is a coupled model that involves five sub-systems represented by five ordinary differential equations and associated state variables. The sub-systems are internally coupled, represented through several constitutive relationships (see Table 3 for the expressions resulting from calibration). In the case of irrigation area, population size and reservoir storage, the model is implemented in a quasi-distributed way, dividing the study domain into three settlements. This brings about additional couplings, involving the one-way exchanges of water (in the downstream direction only), and the two-way exchanges of human populations. As already mentioned, the ecologic and environmental awareness sub-systems are lumped systems, representing a domain that is downstream of the study domain.

Figure 4 conceptualizes how the systems are coupled with each other, and the associated feedback loops. The hydrology equation simulates the capacity of reservoir storage that is available for irrigation. Increase of reservoir storage capacity contributes to an increase of irrigated area per capita, $a_{i}$, in a given region, as reflected in the relationship $\alpha_{\mathrm{s}}(S)$ in Eq. (1). The expansion of irrigated area has a self-magnifying effect: it increases wealth, which is assumed to lead to the creation of a demand for and the ability to adopt new or better technologies.

In this model, wealth is expressed in terms of the agricultural per capita gross basin product (GBP), $P_{\mathrm{GB}}$, for the whole basin (combined value for all settlements). It is defined as the product of crop price, $f_{\mathrm{p}}$, crop yield per unit area, $\gamma_{\mathrm{r}}(T)$, and the weighted average of the irrigated area 


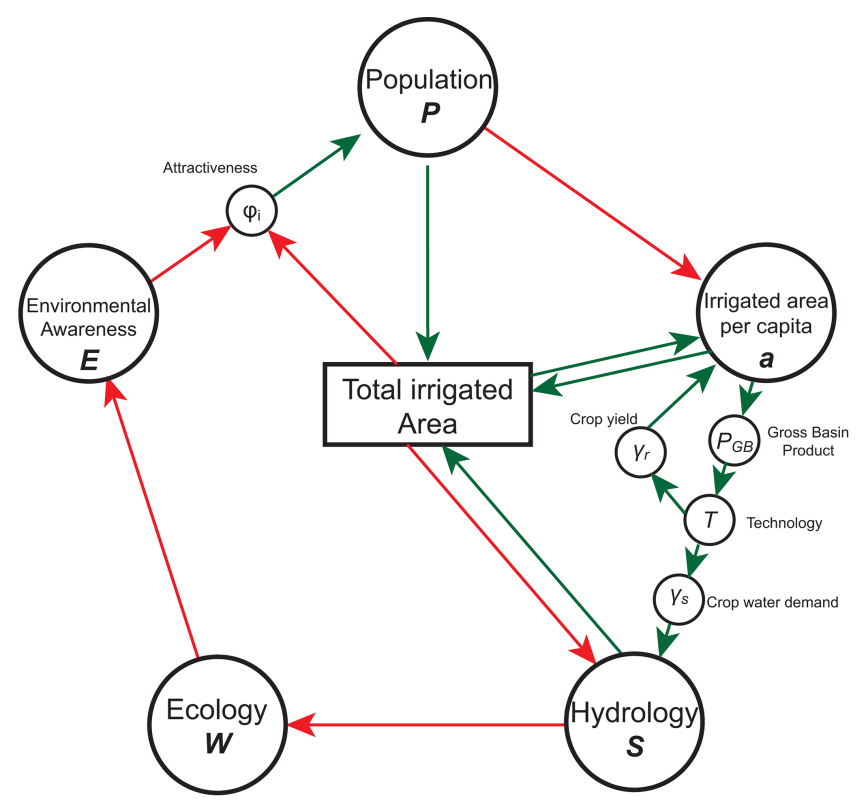

Figure 4. Conceptual framework coupling the five subsystems (hydrology, population, irrigation, ecology and environmental awareness) and the cross-system feedbacks. Green: positive feedback; red: negative feedback.

per capita, $a_{i}$, obtained from Eq. (1):

$$
P_{\mathrm{GB}}=\frac{\gamma_{\mathrm{r}}(T) f_{\mathrm{p}} \sum_{i=1}^{M}\left(a_{i} N_{i}\right)}{\sum_{i=1}^{M} N_{i}}
$$

Since we have divided the basin into three sections, $M=3 . T$ is the technology variable. The crop price, $f_{\mathrm{p}}$, is an external input to the model, and the time series of $f_{\mathrm{p}}$ is obtained over the past 100 years for rice (taken here as the notional crop) from the World Bank (World Bank, 2013). Given the estimate of GBP (which is dynamically changing), technology is then expressed as a function of GBP (see, for example, Eicher, 1996; Pande, 2013). We prescribe a relationship between the two as follows:

$T=\left[\lambda_{1}+\lambda_{2} \exp \left(-\eta P_{\mathrm{GB}}\right)\right]^{-1}$.

Note that the parameter values in Eq. (9) are chosen as, $\lambda_{1}=0.1, \lambda_{2}=0.9, \eta=0.07$, so that $T$ is bounded between 1 and 10. Relative to this basin and relative to this time period, $T=1$ represents a low technological level (e.g., primitive society, at an initial phase of a human settlement), and $T=10$ represents the highest possible technological development. We note here that GBP in the above relationship is assumed to be impacted by past technological developments.

Technology, $T$, is thus an endogenous variable that broadly reflects productivity increase due to mechanization, efficient water distribution, planting, improved crops etc. In the model, $T$ is assumed to contribute to three factors that affect agricultural and economic productivity: crop water demand per unit area, $\gamma_{\mathrm{s}}(T)$; crop yield $\gamma_{\mathrm{r}}(T)$, which is the amount of crop produced per unit irrigated area; and irrigated area per capita, $a_{i}$. In the case of $\gamma_{\mathrm{s}}(T)$, a high value of $T$ contributes to water savings, and reduces $\gamma_{\mathrm{s}}(T)$. In the case of $\gamma_{\mathrm{r}}(T)$, a high value of $T$ increases crop yields, $\gamma_{\mathrm{r}}(T)$. Together, improved technology enables more water to be saved per unit area and more crops to be produced per unit area, i.e., by reducing $\gamma_{\mathrm{s}}(T)$ and increasing $\gamma_{\mathrm{r}}(T)$. In addition, technology in the form of mechanization reduces human labor requirement, allowing for more land to be cultivated and managed per capita: in this way, $\alpha_{\tau}(T)$ increases, which in turn increases productivity and wealth. Taken together all of these feedbacks constitute a common positive feedback loop in the coupled socio-hydrologic system.

The productivity of the combined land, water and human resources, through wealth generation and technological advances, contributes to their further exploitation. Over time, such intensification of production contributes to a progressive degradation of the environment, which acts as a control or restraint on further growth. This negative feedback is represented in the model in several ways.

Firstly, expansion of irrigated area leads to a reduction of flows released to the wetlands, contributes to a reduction of storage in these wetlands, and in this way contributes to the damage of the ecology of wetlands. Persistent damage, as measured by the number of days of the year when $W$ falls below the set threshold, sensitizes the population to environmental damage. Thus ecological damage resulting from irrigation area expansion feedbacks to raise awareness in the local and wider community to slow or even reverse the degradation and ultimately protect the environment. This is represented in Eq. (1) in the form of a term, $\alpha_{\mathrm{E}}(E)$, which represents a rate of reduction of irrigation area per capita as a function of environmental awareness.

Secondly, for the basin as a whole, there is another facet to the exploitation of the land and water resources. This is through increased population. Migration from outside and relocation within has been assumed to be driven by "income potential", represented here by "irrigation potential". As people settle in the downstream section and exhaust the area available for irrigation, they migrate upstream, and open up new areas for irrigation, raise demand for water, which then leads to construction of reservoirs. Limited area available for irrigation constrains further growth. However, in addition, the upward expansion of irrigation area, and subsequently the exploitation of water resources through construction of more reservoirs upstream, reduces environmental flows downstream, sharply reducing the recharge of wetlands. The resulting increase of environmental awareness is factored in the model, helping to slow down the upward migration, and accelerating downward movement of all relevant variables. Figure 4 captures the essence of both positive and negative feedback loops that are captured in the model. Even 

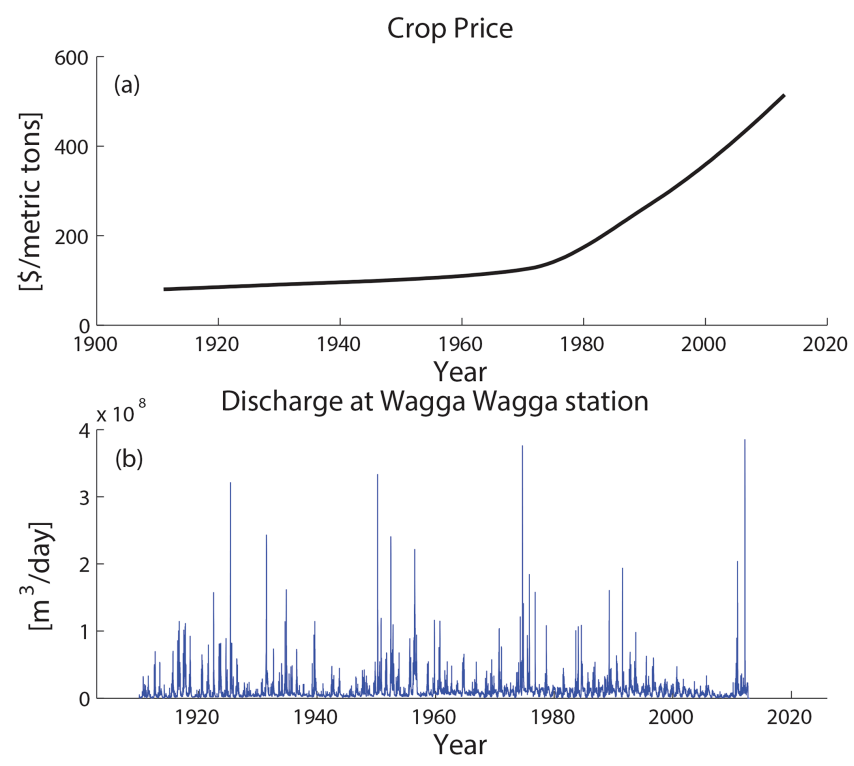

Figure 5. External drivers of the socio-hydrologic system: (a) world food (rice) prices (taken from the World Bank), and (b) measured discharge at Wagga Wagga.

if independently and empirically derived, the organization of the coupled system closely resembles the generic framework proposed by Elshafei et al. (2014).

\subsection{Initial and boundary conditions}

Figure 5 presents time series of measured discharge at Wagga Wagga and of world price for rice over the past 100 years. These, and the average rainfall time series over the study domain, are the only external drivers to the socio-hydrologic model. Upstream flow and rainfall are clearly not impacted by human activity occurring within the MRB. Food price is controlled by global food supply and demand dynamics, and is outside the control of the MRB (i.e., it is exogenous to MRB). All other dynamics are internally, or endogenously, generated on the basis of the assumptions of the model and the assumed constitutive relations. In this paper, we have chosen rice to serve as the surrogate for a general food/crop price. Part of the reason is that rice was already introduced into the MRB at the beginning of the study period, and constitutes over $50 \%$ of the irrigation allocation (Gorman, 2013; Hafi et al., 2005).

As initial conditions, it is assumed that the community begins to grow and expand from the downstream end only and neither humans nor any organized agricultural activities initially existed in the middle stream and upstream sections of the basin. Table 1 presents the initial conditions for all state variables assumed in the model. A simple explicit numerical scheme is used to solve the coupled set of differential equations. The model uses variable time steps: the hydrology and ecology equations are solved on a daily time step,
Table 1. Model initial condition setup.

\begin{tabular}{lrrrr}
\hline \multicolumn{5}{c}{ Model initial condition $(t=0)$} \\
\hline Variables & Unit & $\begin{array}{r}\text { Downstream } \\
\text { settlement }\end{array}$ & $\begin{array}{r}\text { Mid- } \\
\text { stream } \\
\text { settlement }\end{array}$ & $\begin{array}{r}\text { Upstream } \\
\text { settlement }\end{array}$ \\
\hline$S$ & {$\left[\mathrm{~m}^{3}\right]$} & 0 & 0 & 0 \\
$N$ & {$\left[\mathrm{capita}^{2}\right.$} & 5000 & 0 & 0 \\
$a_{i}$ & {$\left[\mathrm{~km}^{2} \mathrm{capita}^{-1}\right]$} & 0.03 & 0 & 0 \\
$E$ & {$[-]$} & 0 & 0 & 0 \\
$W$ & {$\left[\mathrm{~m}^{3}\right]$} & 5000 & - & - \\
\hline
\end{tabular}

whereas all other equations are solved with an annual time step. Table 2 presents the definition of the parameter values used in the model and prescribed magnitudes in the model. Note that the constitutive relations and their parameter values are calibrated and the results are presented in Table 3. Kandasamy et al. (2014) illustrated the pendulum swing in the Murrumbidgee in terms of variations of reservoir capacity, population size, irrigation area and environmental flows, which are reproduced here in Fig. 6a-d to provide context. The aim of the model presented here is to capture broad features of these trends (in space and time) and to gain deeper insights that might be generalized to other places.

The model includes several constitutive relations that make it determinate. These include: $\alpha_{\tau}(T) \alpha_{\mathrm{s}}\left(S_{i}\right) \alpha_{\mathrm{E}}(E)$, $\psi_{\mathrm{m}}(\varphi)$ and $\varepsilon(n)$. Additionally, to complete the specification of the problem we have to prescribe other relations such as those of $T(\mathrm{GBP}) \gamma_{\mathrm{s}}(T)$ and $\gamma_{\mathrm{r}}(T)$. It is premature to prescribe these constitutive relations a priori. For the purpose of this study these constitutive relations are "tuned" so that the model is able to mimic the observed, emergent dynamics, as shown in Fig. 6a-d. The data in Fig. 6a-d was taken from Kandasamy et al. (2014), based on (a) water storage development in the MRB (sourced from NSW State Water Corporation), (b) population in the MRB (ABS, 2013a), (c) irrigated area in the MRB (ABS, 2013b) and (d) irrigation flow utilization in the MRB (DWR, 1989; ABS 2013b).

\subsection{Model sensitivity analysis}

The socio-hydrological modeling framework, though parsimonious, has numerous parameters. While this allows flexibility in representing diverse socio-hydrological behaviors, i.e., that it can generate several socio-hydrological realities, it may also lead to equifinality in that it may generate similar socio-hydrological realities, but with different parameter values (Savenije, 2001). A sensitivity analysis of the model with respect to its parameters is therefore important in order to reveal diverse realities that it can reveal, as well as determine how prone it is to equifinality. The benefits of this analysis are threefold. First, we identify redundant, i.e., equifinal parameters. Second, it gives insight on how parameters, fluxes and stocks are connected. Third, it allows us to explore the alternate socio-hydrological realities that 
Table 2. Definitions of the parameters of the coupled human-water system model and the chosen magnitudes of the parameter values.

\begin{tabular}{|c|c|c|c|c|c|}
\hline Variables & Unit & Description & Eq. & Domain & Value \\
\hline$c$ & {$\left[\right.$ day $\left.^{-1}\right]$} & Evironmetal awareness memory correction coefficient & $(18)$ & Population & 0.5 \\
\hline$\beta$ & {$[-]$} & Runoff coefficient & (4) & Hydrology & 0.01 \\
\hline$A^{\mathrm{c}}$ & {$\left[\mathrm{km}^{2}\right]$} & Physical catchment area & (4) & Hydrology & 20000 \\
\hline$\gamma_{\mathrm{s}}$ & {$\left[\mathrm{m}^{3} \mathrm{day}^{-1} \mathrm{~km}^{-2}\right]$} & Crop water demand & (4) & Internal & - \\
\hline$T$ & {$[-]$} & Technology & (8) & Internal & - \\
\hline$\gamma_{\mathrm{r}}$ & {$\left[\mathrm{t} \mathrm{km}^{-2}\right]$} & Crop yield per unit area & (5) & Internal & - \\
\hline$\delta$ & [day $]$ & Drought threshold & - & - & 50 \\
\hline$\mu$ & {$\left[\mathrm{m}^{3} \mathrm{day}^{-1}\right]$} & Wetland recharge threshold & (5) & Ecology & $10^{8}$ \\
\hline$W_{\mathrm{d}}$ & {$\left[\mathrm{m}^{3}\right]$} & Wetland danger threshold & - & Environmental awareness & 300 \\
\hline$n$ & [day $]$ & Days of environmental degradation in one year & (6) & Internal & - \\
\hline$\kappa$ & {$\left[\right.$ day $\left.^{-1}\right]$} & Wetland leakage rate & (5) & Ecology & 0.001 \\
\hline$\psi_{\mathrm{n}}$ & {$\left[\right.$ day $\left.^{-1}\right]$} & Natural population growth rate & (2) & Population & 0.006 \\
\hline$\psi_{\mathrm{m}}$ & {$\left[\right.$ day $\left.^{-1}\right]$} & External migration rate & (2) & Population & - \\
\hline$\psi_{\mathrm{r}}$ & {$\left[\right.$ day $\left.^{-1}\right]$} & Internal relocation rate & (2) & Population & - \\
\hline$A_{\max }$ & {$\left[\mathrm{km}^{2}\right]$} & Effective irrigated area & - & - & 2.000 \\
\hline$\zeta$ & {$[-]$} & Environmental awareness dissipation rate & - & - & 0.005 \\
\hline$\varphi_{i}$ & {$\left[\mathrm{~km}^{2}\right.$ capita $\left.^{-1}\right]$} & Attractiveness of settlement $i$ & (3) & Population & - \\
\hline$\varepsilon$ & {$\left[\right.$ day $\left.^{-1}\right]$} & Rate of change of environmental awareness & (7) & Environmental awareness & - \\
\hline$r$ & {$\left[\right.$ cap km $^{-2}$ day $\left.^{-1}\right]$} & Attractiveness coefficient & (4) & Population & 1 \\
\hline$Q$ & {$\left[\mathrm{~m}^{3}\right.$ day $\left.^{-1}\right]$} & Discharge & (5) & Hydrology & - \\
\hline$f_{\mathrm{p}}$ & {$\left[\$\right.$ ton $\left.^{-1}\right]$} & Product of crop price & (7) & - & - \\
\hline
\end{tabular}

Table 3. Calibrated constitutive relations needed to complete model specification.

\begin{tabular}{lr}
\hline Domain & Calibration constitutive relationship \\
\hline Technology & $T=\left[0.1+0.9 e^{\left.-0.07 P_{\mathrm{GB}}\right]^{-1}}\right.$ \\
Irrigation & $\alpha_{\mathrm{S}}(S)=0.42 \times 10^{-8} S$ \\
Irrigation & $\alpha_{\mathrm{T}}(T)=0.06-0.0732 e^{-0.2 T}$ \\
Irrigation & $\alpha_{\mathrm{E}}(E)=0.03\left[e^{-E}-1\right]$ \\
Irrigation & $\gamma_{\mathrm{S}}(T)=8000 e^{-0.4 T}+4500$ \\
Irrigation & $\gamma_{\mathrm{r}}(T)=\left[0.75+0.833 e^{-0.75 T-0.75}\right]^{-1}$ \\
Population & $\psi_{\mathrm{m}}\left(\phi_{i}\right)=0.145-0.4205\left[1+\exp \left(6.35 \psi_{i}+0.635\right)\right]^{-1}$ \\
Environmental awareness & $\varepsilon(n)=\left\{\begin{array}{l}0.0019\left\{e^{0.0085 n}-1\right\} ; n>0 \\
-\zeta ; n=0\end{array}\right.$ \\
\hline
\end{tabular}

the presented modeling framework can generate. To accomplish this, we used a variance-based method, similar in spirit to Sobol $(1993,2001)$. Over the last few years, various authors have used variance-based sensitivity analysis to assess complex hydrologic or ecologic system models (e.g., Tang et al., 2007; Rosero et al., 2010; Bois et al., 2008; Song et al., 2012). The variance-based index that we use to assess parameter sensitivity of model outcomes, $S_{i}$, is computed as

$S_{i}=\frac{V_{i}}{V(Y)}$ where $V_{i}$ is the variance of model outcome statistic $Y$ (for, e.g., the mean squared error in simulating the best fitting population time series) when the $i$ th parameter is varied and $V(Y)$ is the sum of variances $V_{i}$ over all the parameters. We note here that $V(Y)$ is the sum taken over parameters one at a time, and not over all possible combinations of parameters.

All parameters are varied within a given range, which can be seen in Table 4. Every parameter is varied (uniformly sampled from the corresponding parameter range) one at the time, yielding corresponding modeled time series for outcome variables: population, irrigated area, storage, wetland 

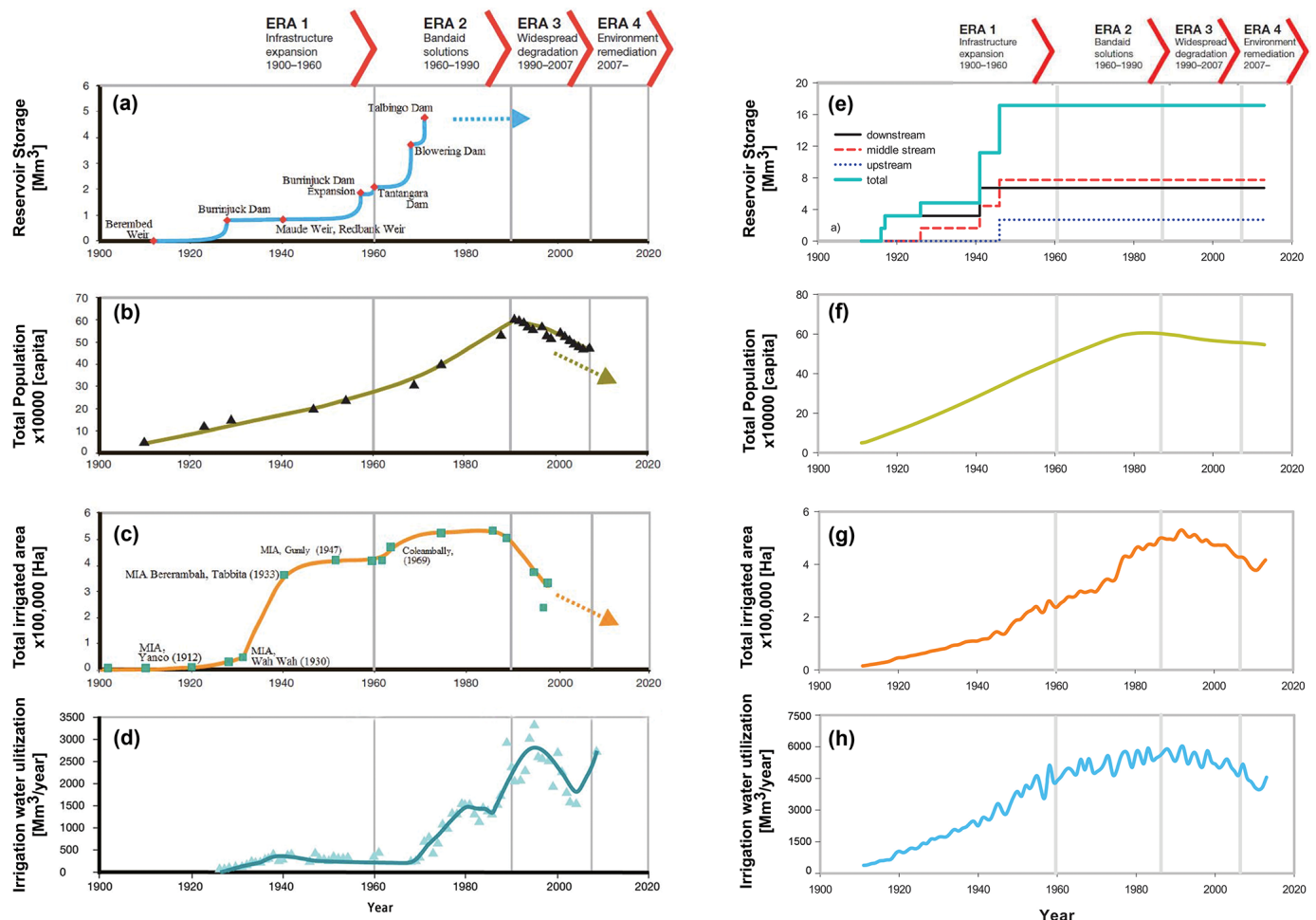

Figure 6. Observed (based on Kandasamy et al., 2014) and modeled pendulum swing in the Murrumbidgee basin during the study period (1910-2013). Observed times series of (a) reservoir storage, (b) total population within basin, (c) total irrigated area, and (d) irrigation water use. Modeled time series of (e) expansion of reservoir storage capacity, (f) total human population, (g) total irrigated area, and (h) irrigated water use.

storage and environmental awareness. These are compared with the best fitting model outcome to determine the root mean squared error (RMSE), yielding a RMSE per outcome variable for all samples of the parameter $i$. The variance of the RMSEs, $V_{i}$, corresponding to the samples of parameter $i$ is then calculated. The variances of these RMSEs over the parameters sampled are then summed to obtain the following equation for the sensitivity of a model outcome to the $i$ th parameter,

$S_{i}=\frac{V_{i}}{\sum_{i=1}^{d} V_{i}}$

where $i$ is the tested parameter, $d(=15)$ is the total number of parameters $(i=1, \ldots, d), V_{i}$ is the variance of RMSEs corresponding to parameter $i$, and $S_{i}$ is the sensitivity index for the $i$ th parameter. The results of the model are used to explore sensitivity of model outcomes to parametric perturbations and the ability of the presented model to simulate diverse socio-hydrological realities.

\section{Results and discussion}

The results of model implementation in the Murrumbidgee basin are presented in four parts: (i) the resulting model- predicted temporal (and spatial) dynamics of the state variables and fluxes, (ii) outcomes of the constitutive relations obtained after matching the observed dynamics, (iii) presentation of the dynamics of other internal variables to help provide insights into the co-evolutionary dynamics, and (iv) the sensitivity and robustness of the model.

\subsection{Temporal and spatial dynamics of the state variables and fluxes}

Figure 6e presents the time variations of reservoir capacity, population size, irrigation area, and water extraction for irrigation over the 100-year period to mirror the corresponding observed trends shown in Fig. 6a-d. Figure 6e also shows the upstream migration of reservoir capacity. In both Figs. $6 \mathrm{e}-\mathrm{h}$ and 7 , we divide the study period into the four major eras identified by Kandasamy et al. (2014). Figure 7 presents the calibrated constitutive relations. The functional forms of these constitutive relations are presented in Table 3. The results demonstrate that the model is able to mimic in a "general" way the temporal trends in the observed dynamics of water resources, area under irrigation, population size, including the "pendulum swing".

However, by itself this is not claimed to be a unique result of the model, given that these are calibrated results. The 
Table 4. Parameters tested during the sensitivity analysis, including the minimum and maximum values of the tested parameter range.

\begin{tabular}{lrrrr}
\hline Variables & Description & Value & Min. & Max. \\
\hline \multicolumn{5}{c}{ Environmental awareness } \\
$\beta$ & memory correction coefficient & 0.5 & 0 & 1 \\
$A^{\mathrm{c}}$ & Runoff coefficient & 0.01 & 0 & 1 \\
$\delta_{1}$ & Physical catchment area & 20000 & 0 & 40000 \\
$\delta_{2}$ & Drought threshold & 50 & 1 & 500 \\
$\delta_{3}$ & Drought threshold & 50 & 1 & 500 \\
$\mu$ & Drought threshold & 50 & 1 & 500 \\
$W_{\mathrm{d}}$ & Wetland recharge threshold & $10^{8}$ & $10^{6}$ & $10^{10}$ \\
$\kappa$ & Wetland danger threshold & 0.03 & 0 & 0.1 \\
$\psi_{\mathrm{n}}$ & Wetland leakage rate & 0.001 & 0.001 & 0.05 \\
$A_{1, \max }$ & Natural population growth rate & 0.006 & 1 & 10000 \\
$A_{2, \max }$ & Max. effective irrigated area & 2000 & 1 & 10000 \\
$A_{3, \max }$ & Max. effective irrigated area & 2000 & 1 & 10000 \\
$\zeta$ & Max. effective irrigated area & 2000 & 1 & 0.2 \\
$r$ & Environmental awareness dissipation rate & 0.005 & 0 & 1 \\
\hline
\end{tabular}

complexity of the model and the many degrees of freedom available to it, can lead to simulation of patterns that are different from the observed pendulum swing. While high complexity is desirable to simulate a rich class of emergent patterns, such models when calibrated, especially for sparsely gauged basins (in terms either of socio-economic or hydrological data), may not reliably predict the dynamics driven by future yet unseen exogenous forcing. See for example Sivapalan et al. (2003), Jakeman and Letcher (2003), Fenicia et al. (2008), Pande et al. (2012), Pande (2013), and Arkesteijn and Pande (2013) for extensive analyses of the relationships between model complexity, model structure deficiency, prediction uncertainty. Furthermore, the differences in the shapes of the curves between observations and predictions, especially in the case of irrigation area, points to model improvements that can still be made: for example, the assumption that attractiveness level is a function of irrigation potential may have to be improved with the hindsight of additional data. In this way these modelling efforts can also give guidance and focus to future data collection efforts and analyses.

\subsection{Outcomes of the constituent relations}

Regardless of how well the model is able to reproduce the observed dynamics, we are more interested in answering the following questions. How did the observed dynamics unfold? What is a plausible explanation for the observed dynamics? What insights can be gained through the implementation of the model? However we acknowledge that, given the complexity of the model and the associated equifinality issues, what we can learn from the calibrated model is just one possible explanation, one of several.
Figures 8 to 10 provide possible answers to these questions through recourse to the simulated dynamics of several internal variables, which may provide insights into how the observed hydrologic and human process dynamics emerged through the human-water interactions and feedbacks. Exploration of the causes of the observed behavior must begin with the recognition that the only external drivers are: (i) climate, although in this case this is replaced by the water inflows from the upstream catchment area, as measured at Wagga Wagga (which acts as the surrogate to climate), and (ii) the time series of world rice prices. Apart from these, the entire dynamics is endogenous or internally generated, and emerged in response to these external drivers.

The figures illustrate the complex feedbacks that the model incorporates. Figure 8 is a demonstration of a positive feedback loop mediated by human innovation, i.e., technology, while Fig. 10 is a negative feedback loop that is mediated by human awareness of the environment. Figure 9 demonstrates the adaptation of human population, through migration, to such feedbacks through migration. Therefore, human migration, in a sense, facilitates the swing between the positive and negative feedbacks.

The results in Fig. 6 showed that the total irrigation area steadily increased until the turnaround that happened around 1980. This corresponds with the emerging appearance of environmental degradation, partly due to agricultural activities (Kandasamy et al., 2014). Figure 8 expands upon the modeled dynamics. Irrigated area per capita, which constitutes one of two major inputs for agricultural production (i.e., land and water), contributes to wealth generation. Higher gross basin production per capita implies higher income for households in the community, which through investment in education and training fuels human innovation. Newer agricultural technologies are either invented or adopted that increase crop 

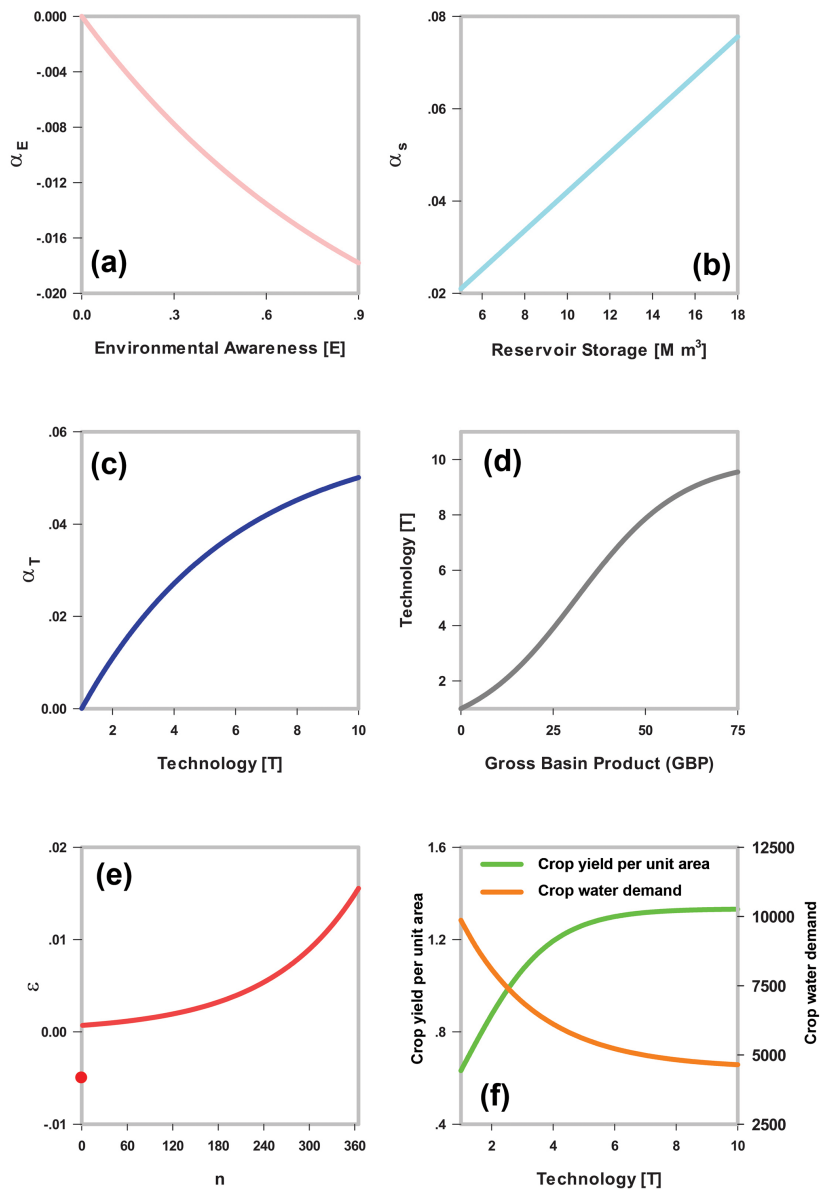

Figure 7. Calibrated constitutive relationships: (a) environmental awareness $E$ vs. 1315 population growth rate $\alpha_{\mathrm{E}}$; (b) reservoir storage $S$ vs. population growth rate $\alpha_{\mathrm{S}}$; (c) technology $T$ vs. population growth rate $\alpha_{\mathrm{T}} ;$ (d) gross basin product vs. technology $T$; (e) water shortage days $n$ vs. rate of change of environmental awareness $\varepsilon$ (red dot represents the forgetting rate); (f) technology $T$ vs. crop water demand $\gamma_{\mathrm{s}}$ and crop yield $\gamma_{\mathrm{r}}$ (see Table 2 for more details).

yields and crop water demand per capita. Humans thus enhance their capacity to irrigate more land per capita through innovation in all three sections of the MRB. This in turn feeds back to higher agricultural production per capita, fueling the positive feedback even further (Fig. 8).

\subsection{Co-evolutionary dynamics}

The next question is, how did the turnaround happen? In spite of technological innovation, the attractiveness of a settlement reduces with increasing area being irrigated per capita. This influences the pattern of human migration both from outside and from within different sections of the basin (Fig. 9). Given that initially the upstream areas were not inhabited, humans first exploited the potential of downstream areas before migrating upstream. Increased migration over time eventually makes upstream areas less attractive as well. The reduction
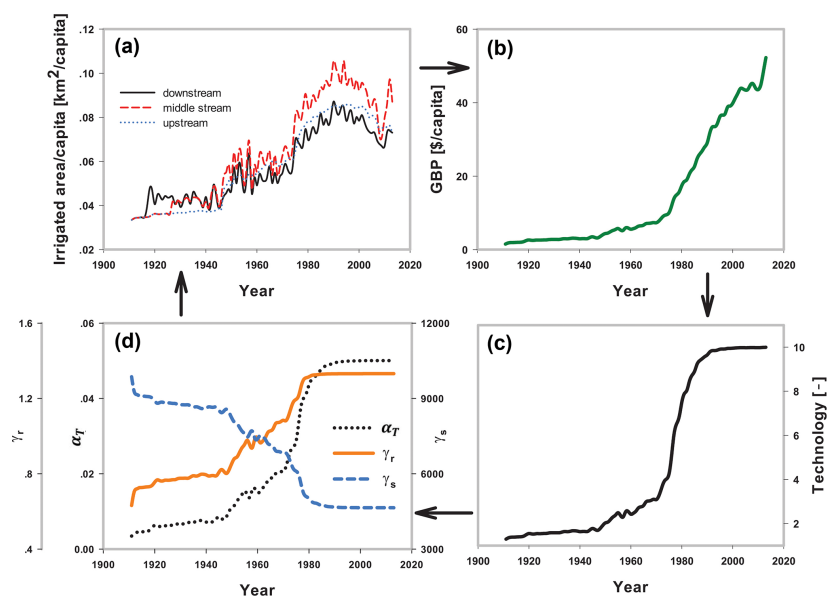

Figure 8. Time variation of socio-economics: (a) irrigated area per capita for each of the three settlements; (b) gross basin product in $\$ /$ capita; (c) crop yield $\gamma_{\mathrm{r}}$, crop water demand $\gamma_{\mathrm{s}}$ and the technology factor $\alpha_{T} ;$ and (d) technology $T$.
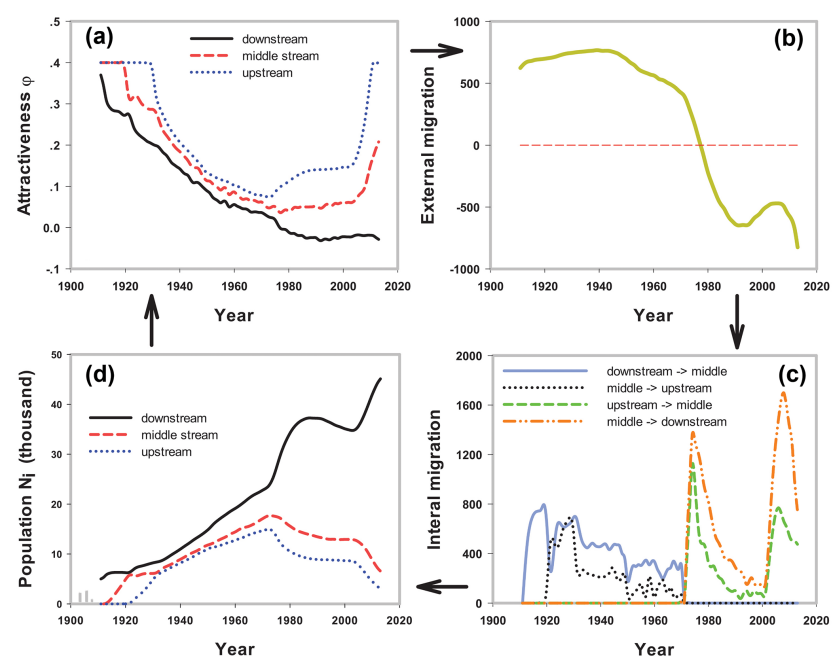

Figure 9. Time variation of population dynamics: (a) attractiveness factor for each of the three settlements; (b) rate of external migration; (c) rates of internal relocation between the three settlements; and (d) size of population in the three settlements.

in irrigation potential due to population growth also reflects excessive exploitation of the basin as a whole resulting in, for example, lower environmental flow. The latter, also described by Kandasamy et al. (2014) is one of the direct reasons for environmental degradation. Subsequently, humans attempt to balance their urge to maximize (technology mediated) agricultural income and minimize environmental impacts of such activities. They do so by gradually migrating back to downstream sections as they become more aware of environmental degradation. As a result, the total population in the two upstream sections reduces while the population in the most downstream section increases at an even higher rate. Consequently, the attractiveness of the two upstream sections 

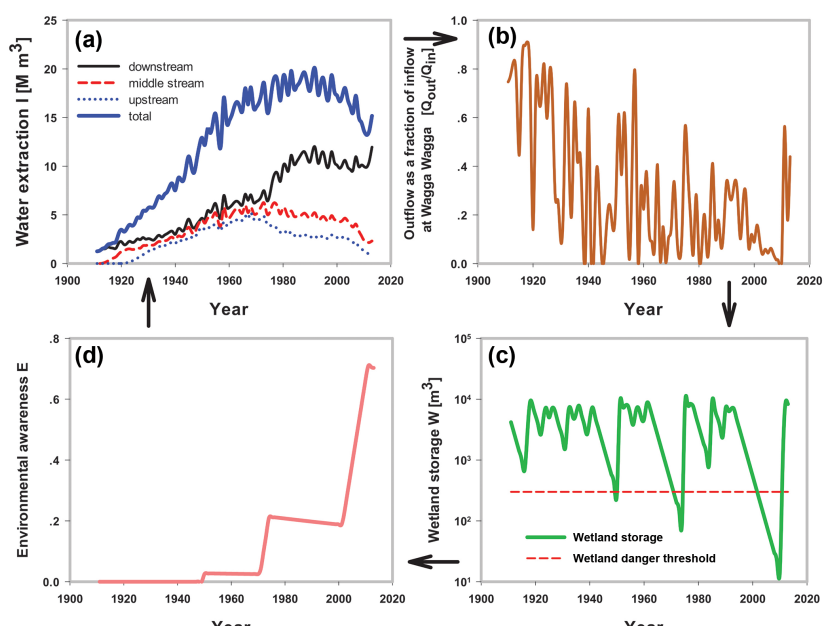

Figure 10. Time variation ecology-environmental awareness: (a) rates of water extraction in the three settlement and total rate of water extraction; (b) environmental (out)flow to downstream wetlands as a ratio of inflow at Wagga Wagga; (c) wetland storage and wetland danger threshold; and (d) environmental awareness.

begins to pick up towards the end of 2010 while the attractiveness of the most downstream section does not recover (although it stabilizes).

Figure 10 documents the modeled dynamics of environmental awareness in greater detail. The migration from downstream section to the middle and upstream sections results in water extraction in the two upstream sections that first increases until 1970s and then declines. The water extraction in the most downstream section never declines due to the ensuing migration pattern as demonstrated in Fig. 9. As a result, outflow as a fraction of inflow declines until the 1970s. This declining outflow influences the wetland storage, causing it to severely fall below the critical threshold around 1970. This appears to be a historical moment as it strongly sensitizes the population to environmental degradation due to their production activities and begins to influence the decision of humans where to migrate. Migration to upstream sections drops sharply. Instead they decide to migrate back to the downstream section in an attempt to restore ecosystem services, in a manner that balances nature's demand with their demand to maximize individual livelihood. This feeds back into water extraction patterns, which are now strongly influenced by environmental awareness. As individuals become more aware of their environment, more migrate from upstream sections to the downstream sections in an attempt to restore ecosystem services. By around 2010, the community is extremely sensitive to environmental degradation. This was also concluded by Kandasamy et al. (2014), where it was found that in 2007 the era of remediation and environmental restoration started.

These results, once they are organized in this way, point to the presence of two competing drivers that are behind the pendulum swing, as shown in Fig. 11a. The first one involves a positive feedback loop related to the economic system: in this loop the main resources of water, land and humans are combined to produce wealth (in the form of agricultural crop). The wealth leads to advances in technology, which contributes to the attractiveness of the area for expansion of agriculture, which attracts people, and the cycle continues in this way. Liu et al. (2014) have explained this growth in terms of the concept of human productive force, illustrating it through the co-evolution of humans and water in the Tarim basin in western China over the past 2000 years. The positive feedback loop dominated the Murrumbidgee for the first 80 years.

The second driver, part of the negative feedback loop, reflects nature's reaction to the exploitation of water and land. As more and more water is extracted from the river, and more and more land is put to irrigated agriculture, both the riverine and terrestrial environments begin to degrade, and after some time, they begin to impact the farmers either directly (through reduced productivity of the land, cost of the environmental degradation) and indirectly through increased environmental awareness (both locally and globally, through environmental lobbies and through government intervention). In the case of the Murrumbidgee, this negative feedback became exacerbated due to a persistent severe drought that happened in the 2000s, forcing the hand of humans, as if nature's restorative forces are demanding action from the community.

Consequently, we argue that the "pendulum swing" phenomenon is the result of the self-organization of humanwater system, which we claim is a result of balancing productive forces that appeal to individual preferences for wealth and the restorative forces that aim to preserve the natural environment. On the production side, the goal is to utilize water for enterprise and profit and the community's economic wellbeing. On the restorative side, the goal is to conserve water to satisfy "nature's demand" (e.g., biodiversity, wetland ecology). If nature's demand is not met, extreme events such as droughts have the ability to magnify the effects, then requiring human intervention.

Either way, the competition between water for humans and water for the environment is still principally mediated by humans, acting for themselves and acting for the environment. As indicated in Fig. 11a, this is played out in the arenas of technology change and environmental awareness, both facets of human enterprise and endeavor. The pendulum swing resulting from the competition between the productive and restorative forces is consistent with the Taiji-Tire model outlined in the companion paper by Liu et al. (2014), shown in Fig. 11b, except that the particular features observed in the Murrumbidgee are a reflection of the particular climatic, socio-economic and politico-legal setup of the region. 
(a)

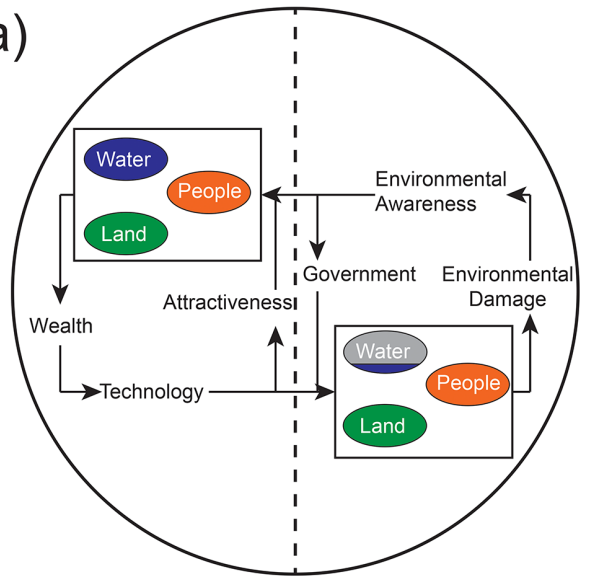

(b)

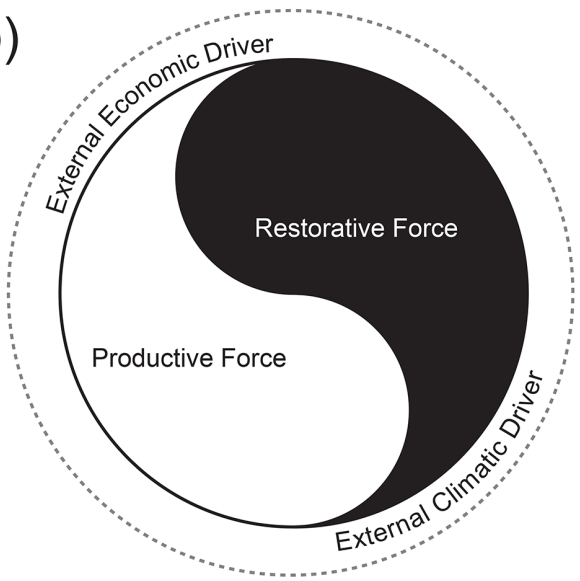

Figure 11. (a) Positive and negative feedback loops that are built into the model; (b) Taiji-Tire model representation of the dynamics operating within the Murrumbidgee River basin (the Taiji-Tire model is a concept borrowed from Liu et al., 2014).
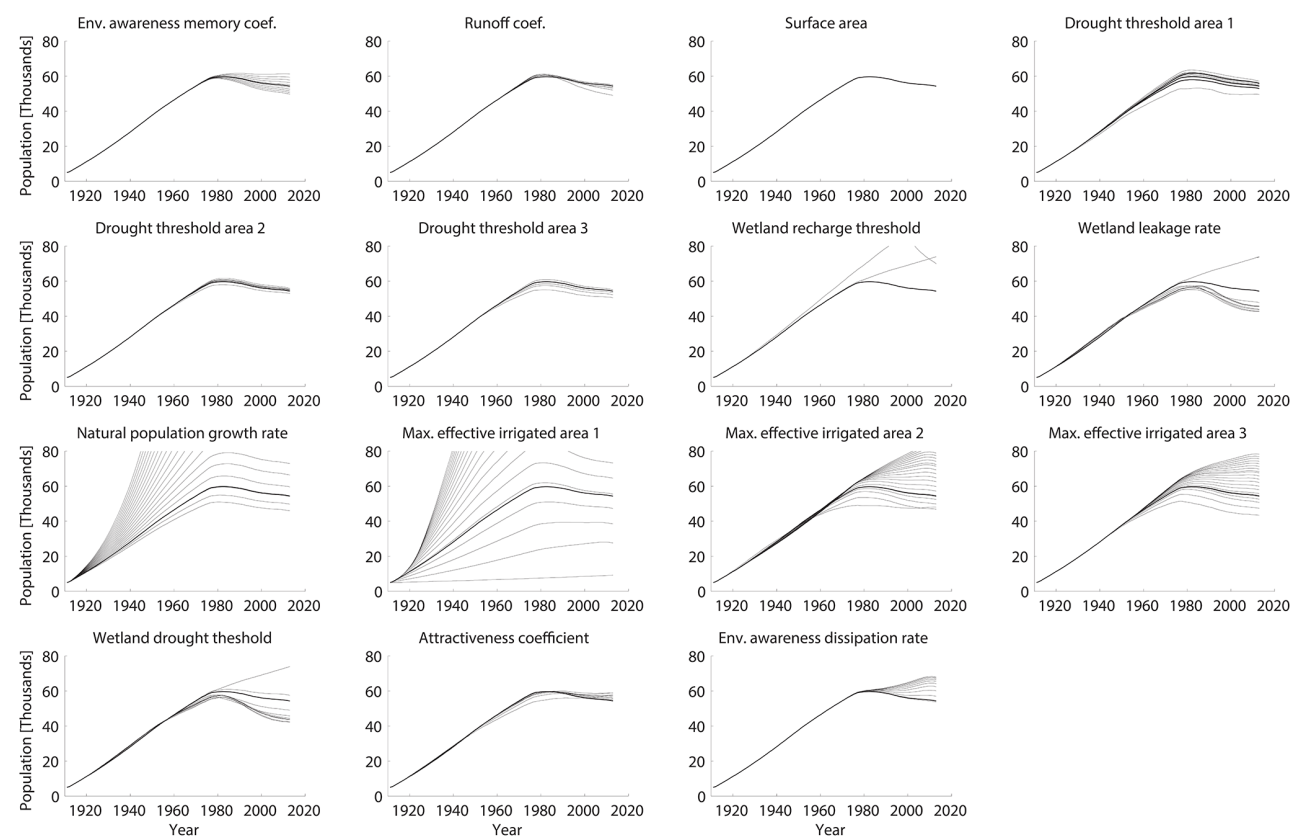

Figure 12. Modeled time series of total population for different values of the tested parameters. All subplots correspond to one tested parameter, the separate lines represent model outcome for a given parameter.

\subsection{Model sensitivity and robustness}

We have performed a sensitivity analysis in order to assess alternate realities that the socio-hydrologic model can generate and to identify sensitive parameters of the model. Table 4 shows the 15 parameters of the model that are analyzed and their assumed realistic ranges. Figure 12 shows the variation in one outcome, variable, namely population, as a result of the variation of parameters one at a time. Each subfigure shows the variation in the simulated population when one of the 15 parameters is varied within the ranges prescribed in Table 4. It shows that not all parameters have a significant influence on the model outcome. The most sensitive parameters are natural growth rate $\psi_{\mathrm{n}}$ and maximum effective irrigated area $A_{1, \max }$. It is not just the timing and the magnitude of the population time series that is affected when parameters are varied. It appears that the model is able to simulate three different modes of a socio-hydrologic system, i.e., continued growth and growth followed by decline and no growth, under different parametric perturbations. In most cases, the parameter selections lead to outcomes that are relatively close to the best fit with reality, i.e., growth followed by a decline (Fig. 12, thick line). However, perturbations with several parameters (e.g., high natural growth rate $\psi_{\mathrm{n}}$, low maximum 


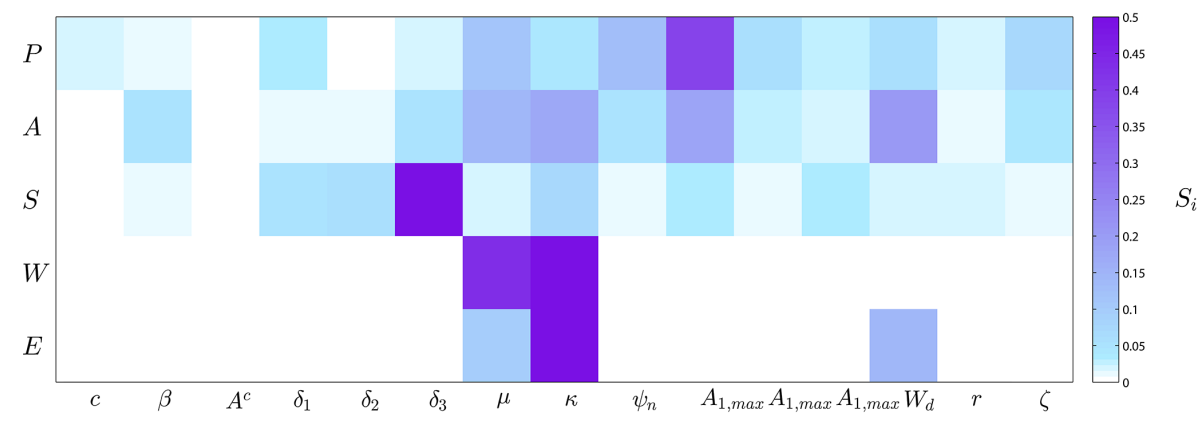

Figure 13. Sensitivity index Si for all parameters, indicating the sensitivity of population $N$, irrigated area $A$, storage $S$, wetland storage $W$ and environmental awareness $E$ to the parameter selection.

effective irrigated area $A_{1, \max }$, or high wetland leakage rate $\kappa)$ lead to time series that resemble continued growth. On the other hand, perturbation with some other parameters (e.g., high maximum effective irrigated area $A_{1, \max }$ ) lead to low population change along with no development in the basin.

Figure 13 shows the sensitivity index of all system model outputs (population, irrigated area, storage, wetland storage and environmental awareness) to parametric variations. It shows that wetland storage $W$ and environmental awareness $E$ are sensitive to only a few parameters. This is to be expected since only a few of the model equations are connected to $W$ and $E$. The parameters that have the largest influence are the wetland leakage rate, the wetland recharge threshold and the wetland danger threshold. Population $N$, irrigated area $A$ and storage $S$ are sensitive to more parameters. The population outcome is highly sensitive to maximum effective irrigated and the natural population rate. These parameters limit the growth potential of the population. When this is increased or decreased, it significantly affects the irrigation potential, the growth and the speed of saturation of the basin. For example, with a larger natural population growth rate, it is likely that the carrying capacity of the system will be reached sooner. Finally, Fig. 14 presents the three different modes of the various model outcomes that the model can converge to under parametric perturbations. One of the modes is the optimal and most realistic of the outcomes, which is similar to Fig. 6. The other mode is one of apparent unbounded growth. When the natural population growth is high, the population and the irrigated area start to grow exponentially. As this development makes the society less resilient to droughts, the storage is increased as well. However, the modeled time frame is too short to investigate whether this will be followed by a dispersal of the system. The third mode is that of no growth. This happens when the maximum effective irrigated area is low and very little potential for agricultural development exists. The incentive for people to migrate and further develop the MRB is then low. Figure 14 shows how the three modes of population, irrigated area and storage are highly inter-connected. For all three, the modes occur for similar parameter selections. The modes for wetland storage occur when the wetland recharge threshold $\mu$ are high or low. A higher $\mu$ requires higher river discharge before flooding occurs. The opposite happens when $\mu$ is low. The environmental awareness is most strongly affected by the Wetland danger threshold $W_{\mathrm{d}}$.

The sensitivity analysis shows that the model results are (in some cases strongly) affected by parameter selection. This means that the modeling framework may provide equifinal representations of a socio-hydrological reality. The value of field data in such cases cannot be overemphasized. Another interesting finding of the sensitivity analysis is the discovery of three system modes that the model can replicate. This means that the framework allows the flexibility to model diverse socio-hydrological realities. This highlights how socio-hydrologic modeling might be used to simulate other coupled human-water systems.

The development of the model presented in this paper, including the performed sensitivity analysis, shows the potential of using socio-hydrologic modeling to explain observed dynamics in human-water coupled systems. Our model is fundamentally sound conceptually, and is in line with other socio-hydrologic models (e.g., Di Baldassarre, 2013b; Srinivasan, 2013; Elshafei et al., 2014; Liu et al., 2014).

\section{Conclusions}

This paper presents a socio-hydrologic modeling framework that has contributed new insights into the drivers of the coevolution in the Murrumbidgee River basin. We used a simple coupled model that attempted to mimic the human-water system. A series of simplifying but plausible assumptions were made (e.g., productivity, growth, migration, water use, ecosystem health, environmental awareness) to configure the model to be able to mimic human-water interactions at a generic level. Clearly, such a parsimonious but rudimentary model cannot match the fine reality in the Murrumbidgee, which is far more complex. Nonetheless, the model has sufficient degrees of freedom and is mathematically complex. It is possibly because of this that the model development and implementation brought out key elements that control 

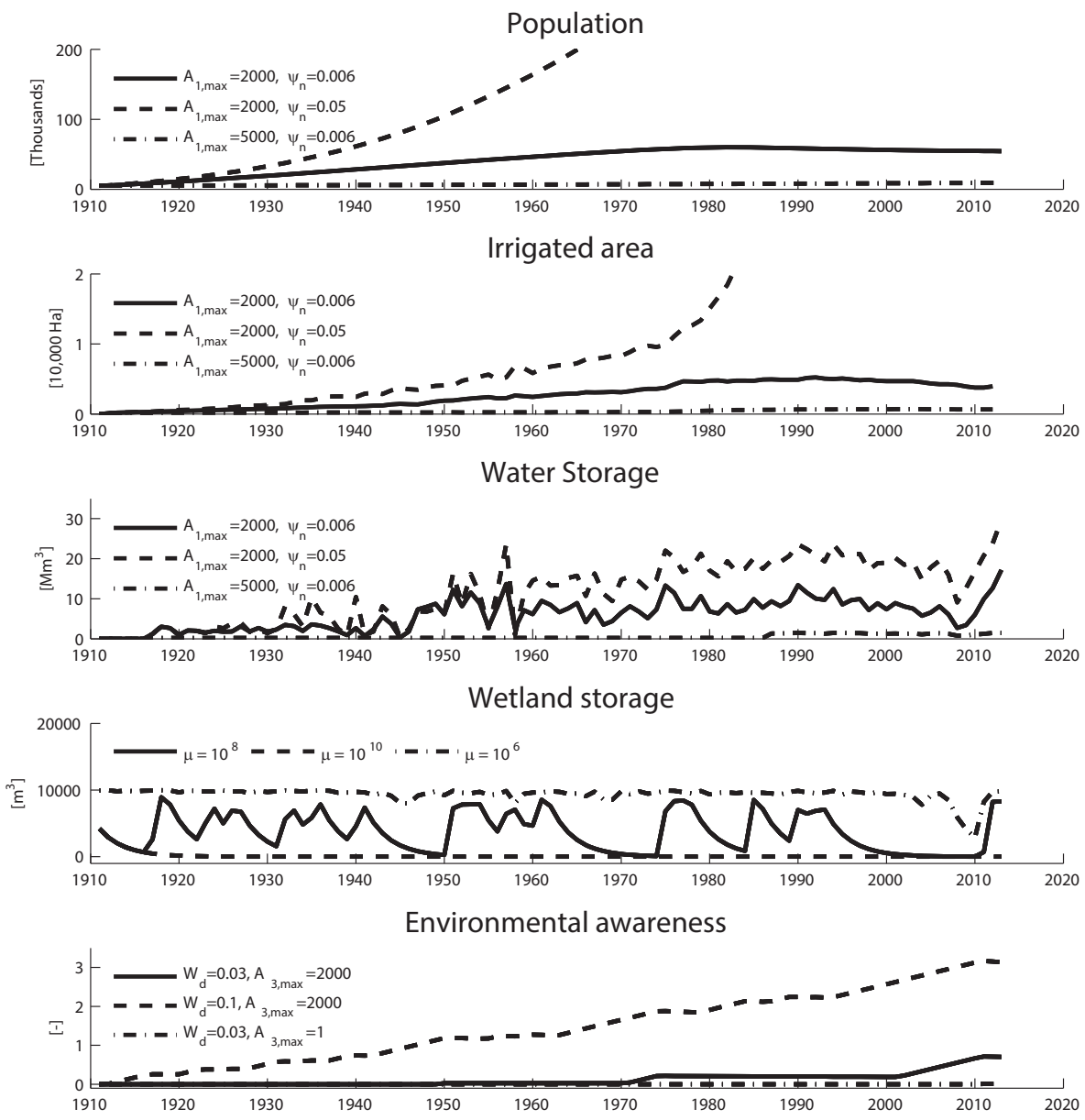

Figure 14. Three model modes for population, irrigated area, water storage, wetland storage and environmental awareness: realistic (solid), increasing (dashed) and declining (dash-dot).

the dynamics and organizing principles that may help frame human-water dynamics, not only in the Murrumbidgee, but also in other similar river basins. We therefore encourage the use of our presented approach to other river basins to be able to eventually arrive at generic socio-hydrologic concepts.

The model had two external drivers: one climate related and the other socio-economic. The rest of the dynamics was endogenously generated in response to the external drivers and the chosen internal model parameterizations. In spite of the details and the specificity of the model to the Murrumbidgee, one aspect stood out. The model results demonstrated that the emergent dynamics, i.e., pendulum swing, was a result of two internal forces. The first one has to do with the economy, which Liu et al. (2014) called "human productive force", which contributed to the growth in exploitation of land, water and human resources, with technology evolution playing an important role. The second one had to do with the environment, which we call here a "environmental restorative force". The exploitation of land and water resources led to environmental degradation, which eventually began to act as a constraint, through the intervention of hu- mans responding to the growth of community environmental awareness. It is the balance of these productive (exploitative) and restorative (environmental) forces that has contributed to the emergent dynamics, as shown in in Fig. 11a. The model built along these lines, along with the results of model simulations, conforms to the Taiji-Tire model enunciated by Liu et al. (2014) based on a historical socio-hydrologic analysis of the Tarim basin in western China, and summarized in Fig. 11b. It also has many similarities to a more generic formulation proposed by Elshafei et al. (2014), wherein human "demand" for water resources and human "sensitivity" for the environment trade off to determine the (enviro-centric or anthropo-centric) "behavioral response" of humans to water use practice.

The paper modeled two keys to the operation and success of a coupled socio-hydrological system. The first was technology, which was the key to increased basin production through exploitation of the land, water and human resources. The second was environmental awareness, which restricted basin production in order to restore the functioning of ecosystem services to certain extent. Both technology 
mediated demand for water and human sensitivity for their environment were modeled in broad terms. Any further advance of socio-hydrologic modeling would therefore require considerable research to quantify them in acceptable ways for the purposes of modeling. The other two key factors were external: climate (as reflected in the water inflows) and external socio-economic conditions (as reflected in the world food prices). Therefore the specificity of any sociohydrologic system, and the differences between several different systems, may be said to arise from the climatic and socio-economic externalities, and the socio-economic and political milieus that govern the evolution of technology and environmental awareness in each of these places.

The sensitivity study with the model showed that the model is sensitive to perturbations of certain parameter values. This revealed interesting sensitivities of model outcomes to selected parameters and shed light on how the sociohydrologic model might be used and improved. Our results showed that the mode of a socio-hydrological system functioning (realistic, unbounded growth or no growth) strongly depends on the selection of certain parameter values, e.g., the natural population growth rate, the maximum effective irrigated area, the wetland recharge rate and the wetland recharge threshold. For the sake of simplicity, we considered these values as static, but one can argue that these might also vary in time and space. These parameters were the main factors that restricted or boosted system development. It would therefore be interesting to confirm these findings with other socio-hydrologic modeling studies. The sensitivity study also revealed the insensitivity of model outcomes to other parameters and hence revealed the possibility of equifinal models that are equally capable of representing observed sociohydrological patterns. Thus the sensitivity analysis revealed some important implications for robust socio-hydrological model identification and parameter selection.

We used a simplified Sobol method for our sensitivity analysis. It did not take into account the sensitivity of model outcomes to perturbations of all possible parameter combinations. A detailed sensitivity analysis may be required to better understand the system dynamics if it is sensitive to perturbations of parameter combinations as well. We would also like to emphasize on the need of studying the stability of sociohydrologic models. As these models consist of coupled nonlinear differential equations, further studying of the stability and sensitivity might shed additional light on how sociohydrologic models might be applied to different area. This is left to future research. Nonetheless our sensitivity analysis revealed the capacity of the model to represent three dominant modes of behavior under the same socio-hydro-climatic forcing.

A natural extension of the analysis would be to explore system dynamics under different socio-hydro-climatic forcings, and initial and boundary conditions. However, the parameters would be kept fixed in this case, for example, fixed at the parameter values found reasonable to represent the socio-hydrological dynamics of the MRB. Such an analysis would explore various co-evolutionary trajectories initiated by different conditions under different forcings in the co-evolutionary space of population, growth, migration, water use, ecosystem health and environmental awareness. Depending on socio-hydrological characteristics, different trajectories might be identified by parts of the co-evolutionary space that these trajectories take the system to in the long run. Such an extended analysis might even reveal sociohydrological characteristics that result in chaotic system dynamics, where co-evolutionary trajectories that are initially close to each other lead to diverse socio-hydrological outcomes in the long-run. A richer set of dominant modes might then be revealed, each depending on the type of forcings, initial and boundary conditions and socio-hydrological characteristics. This is exciting because the presented sociohydrologic modeling framework can then be used to replicate and understand alternate socio-hydrological realities. However, this is left for future research.

In conclusion, this paper has advanced the state of the art of socio-hydrological modeling by making a case for a more general modeling framework that may be transferrable to other coupled human water systems. It used constitutive relations that may also be explicitly derived based on individual decision making (see, for example, Lyon and Pande, 2004). For example, it modeled human migration patterns based on an individual's tendency to maximize economic gains. It models technological innovation and adoption as a function of aggregate production at basin scale based on the assumption that technology and wealth are intrinsic to system dynamics (see, for example, Romer, 1990; Eicher, 1996 on endogenous technological change). The model also incorporated changing values and norms of a society by introducing environmental awareness as another co-evolutionary variable of system dynamics. As a consequence, the model saw the co-evolution of human-water systems as a competition between "productive" and "restorative" forces that emerge from the ensuing dynamics.

Finally, the modeling framework presented here is the first spatially explicit socio-hydrological model that has the capacity to replicate observed patterns of population migration and growth, technological adoption and aggregate production at basin scale. We thus conjecture that the models of this type are capable of mimicking dominant controls on the trajectory of co-evolution of diverse coupled human-water systems since they can incorporate such layers of complexity. However, the model presented in this paper focused exclusively on surface water utilization for agriculture and food production. The situation may be different in groundwater dependent ecosystems or in regions where rain-fed agriculture dominates, which may present different contexts within which to develop socio-hydrologic models. Application of models such as these, suitably adapted to these different contexts, may help bring out fundamental differences in the emergent dynamics that may result. In this paper we show 
how socio-hydrology modeling can be used as a framework to study the co-evolutionary dynamics of complex coupled human-water systems. We hypothesize that this approach, when applied to other systems, can contribute to the development of generic models that can be applied more universally. This is the long-term goal of our research.

Acknowledgements. The work on this paper has in part been supported by a supplementary grant from the US National Science Foundation to the "Water Cycle Dynamics in a Changing Environment: Advancing Hydrologic Science through Synthesis" hydrologic synthesis project (NSF grant EAR:0636043). Data used in the modeling analysis were provided by the State Water Corporation of New South Wales, Australia, and we especially thank Adrian Williams, Gurmeet Singh and Daniel Masters for their assistance with data assembly. THMvE is grateful for the Justus and Louise van Effen Research Grant, which enabled him to spend a few months at the University of Illinois, where this work was initiated. We also thank Seline van der Woude from Delft University of Technology for her help with the sensitivity analysis. The present work was partially developed within the framework of the Panta Rhei Research Initiative of the International Association of Hydrological Sciences (IAHS). We are also thankful to the three anonymous reviewers who provided constructive feedback, which helped us to improve the manuscript significantly.

Edited by: D. Gerten

\section{References}

ABC: Australian Broadcasting Commission: Angry crowd burns copy of Murray-Darling report, available at: http://www.abc.net.au/news/2010-10-13/ angry-crowd-burns-copy-of-murray-darling-report/2296638 (last access: February 2014), 2010.

ABS: Australian Yearbook, Australian Bureau of Statistics, available at: http://www.abs.gov.au/AUSSTATS/abs@.nsf (last access: May 2013), 2013a.

ABS: Australian Bureau of Statistics, available at: http://www.abs. gov.au/ (last access: May 2013), 2013b.

Arkesteijn, L. and Pande, S.: On hydrological model complexity, its geometrical interpretations and prediction uncertainty, Water Resour. Res., 49, 7048-7063, doi:10.1002/wrcr.20529, 2013.

Bois, B. P., Van Leeuwen, C., Wald, L., Huard, F., Gaudillere, J.P., and Saur, E.: Using remotely sensed solar radiation data for reference evapotranspiration estimation at a daily time step, Agr. Forest Meteorol., 148, 619-630, 2008.

Chen, H. and Li, M.: Environmental tax policy, habit formation and nonlinear dynamics, Nonlinear Anal.-Real., 12, 246-253, 2011.

Crutzen, P. J. and Stoemer, E. F.: The Anthropocene, Global Change Newsletter, 41, 17-18, 2000.

Cuypers, J. G. M. and Rademaker, O.: An analysis of Forrester's World Dynamics Model, Automatica, 10, 195-201, 1974.

Davies, E. G. R. and Simonovic, S. P.: Global water resources modeling with an integrated model of the social-economicenvironmental system, Adv. Water Resour., 34, 684-700, 2011.
Di Baldassarre, G., Kooy, M., Kemerink, J. S., and Brandimarte, L.: Towards understanding the dynamic behaviour of floodplains as human-water systems, Hydrol. Earth Syst. Sci., 17, 3235-3244, doi:10.5194/hess-17-3235-2013, 2013a.

Di Baldassarre, G., Viglione, A., Carr, G., Kuil, L., Salinas, J. L., and Blöschl, G.: Socio-hydrology: conceptualising humanflood interactions, Hydrol. Earth Syst. Sci., 17, 3295-3303, doi:10.5194/hess-17-3295-2013, 2013b.

DWR: Water distribution operations in irrigation areas and districts of NSW, New South Wales Department of Water Resources, Gutteridge, Haskins \& Davey, Sydney, 1989.

Eicher, T. S.: Interaction between endogenosu human capital and technological change, Rev. Econ. Stud., 63, 127-144, 1996.

Elshafei, Y., Sivapalan, M., Tonts, M., and Hipsey, M. R.: A prototype framework for models of socio-hydrology: identification of key feedback loops and parameterisation approach, Hydrol. Earth Syst. Sci., 18, 2141-2166, doi:10.5194/hess-18-21412014, 2014.

Falkenmark, M. and Lannerstad, M.: Consumptive water use to feed humanity - curing a blind spot, Hydrol. Earth Syst. Sci., 9, 1528, doi:10.5194/hess-9-15-2005, 2005.

Fedotov, S., Moss, D., and Campos, D.: Stochastic model for population migration and the growth of human settlements during the Neolithic transition. Phys. Rev. E, 78, 026107, doi:10.1103/PhysRevE.78.026107, 2008.

Fenicia, F., Savenije, H. H. G., Matgen, P., and Pfister, L.: Understanding catchment behavior through stepwise model concept improvement, Water Resour. Res., 44, W01402, doi:10.1029/2006WR005563, 2008.

Forrester, J. W.: World Dynamics, Wright-Allen, Cambridge, Massachusetts, 1971.

Gleick, P. H. and Palaniappan, M.: Peak water limits to freshwater withdrawal and use, Proc. Natl. Acad. Sci., 107, 11155-11162, 2010.

Gorman, E.: Growing rice on the Murrumbidgee River: cultures, politics, and practices of food production and water use, 1900 to 2012, J. Austral. Stud., 37, 96-115, 2013.

Grafton, R. Q., Pittock, J., Davis, R., Williams, J., Fu, G., Warburton, M., Udall, B., McKenzie, R., Yu, X., Che, N., Connell, D., Jiang, Q., Kompas, T., Lynch, A., Norris, R., Possingham, H., and Quiggin, J.: Global insights into water resources, climate change and governance, Nat. Clim. Change, 3, 1-7, doi:10.1038/nclimate1746, 2013.

Greif, A. and Laitin, D. A.: A theory of endogenous institutional change, Am. Polit. Sci. Rev., 98, 633-652, doi:10.1017/S0003055404041395, 2004.

Hafi, A., Beare, S., Heaney, A., and Page, S.: Water Options for Environmental Flows, ABARE eReport 05.12, prepared for the Natural Resource Management Division, Australian Government Department of Agriculture, Fisheries and Forestry, Canberra, November, 2005.

Hayami, Y. and Ruttan, V. W.: Factor prices and technical change in agricultural development: The United States and Japan, 1880 1960, J. Polit. Econ., 78, 1115-1141, 1970.

Jakeman, A. J. and Letcher, R. A.: Integrated assessment and modelling: features, principles and examples for catchment management, Environ. Model. Softw., 18, 491-501, 2003. 
Kallis, G.: When is it coevolution?, Ecol. Econ., 62, 1-6, 2007.

Kallis, G.: Coevolution in water resource development: The vicious cycle of water supply and demand in Athens, Greece, Ecol. Econ., 69, 796-809, 2010.

Kandasamy, J., Sounthararajah, D., Sivabalan, P., Chanan, A., Vigneswaran, S., and Sivapalan, M.: Socio-hydrologic drivers of the pendulum swing between agricultural development and environmental health: a case study from Murrumbidgee River basin, Australia, Hydrol. Earth Syst. Sci., 18, 1027-1041, doi:10.5194/hess-18-1027-2014, 2014.

Kelly, R. A. A. J. J., Barreteau, O., Borsuk, M. E., ElSawah, S., Hamilton, S. H., Henriksen, H. J., Kuikka, S., Maier, H. R., Rizzoli, A. E., van Delden, H., and Voinov, A. A.: Selecting among five common modelling approaches for integrated environmental assessment and management, Environ. Modell. Softw., 47, 159$181,2013$.

Knapp, K. C., Weinberg, M., Howitt, R., and Posnikoff, J. F.: Water transfers, agriculture, and groundwater management: a dynamic economic analysis, J. Environ. Manage., 67, 291-301, doi:10.1016/S0301-4797(02)00162-7, 2003.

Kumar, P.: Typology of hydrologic predictability, Water Resour. Res., 47, W00H05, doi:10.1029/2010WR009769, 2011.

Liu, Y., Tian, F., Hu, H., and Sivapalan, M.: Socio-hydrologic perspectives of the co-evolution of humans and water in the Tarim River basin, Western China: the Taiji-Tire model, Hydrol. Earth Syst. Sci., 18, 1289-1303, doi:10.5194/hess-18-12892014, 2014.

Lyon, K. and Pande, S.: The costate variable in a stochastic renewable resource model, Nat. Resour. Modell., 19, 45-66, 2006.

Maneta, M. P., Torres, M. O., Wallender, W. W., Vosti, S., Howitt, R., Rodrigues, L., Bassoi, L. H., and Panday, S.: A spatially distributed hydroeconomic model to assess the effects of drought on land use, farm profits, and agricultural employment, Water Resour. Res., 45, W11412, doi:10.1029/2008WR007534, 2009.

Ostrom, E.: A general framework for analyzing sustainability of social-ecological systems, Science, 325, 419-422, 2009.

Pande, S.: Quantile hydrologic model selection and model structure deficiency assessment 1: Theory, Water Resour. Res., 49, 56315657, doi:10.1002/wrcr.20411, 2013.

Pande, S. and Ertsen, M.: Endogenous change: on cooperation and water availability in two ancient societies, Hydrol. Earth Syst. Sci., 18, 1745-1760, doi:10.5194/hess-18-1745-2014, 2014.

Pande, S., van den Boom, B., Savenije, H. H. G., and Gosain, A. K.: Water valuation at basin scale with application to western India, Ecol. Econ., 70, 2416-2428, doi:10.1016/j.ecolecon.2011.07.025, 2011.

Pande, S., Bastidas, L. A., Bhulai, S., and McKee, M.: Parameter dependent convergence bounds and complexity measure for a class of conceptual hydrological models, J. Hydroinform., 14, 443-463, 2012.

Pande, S., Ertsen, M., and Sivapalan, M.: Endogenous technological and population change under increasing water scarcity, Hydrol. Earth Syst. Sci., 18, 3239-3258, doi:10.5194/hess-18-32392014, 2014.

Pulido-Velazquez, M., Andreu, J., and Sahuquillo, A.: Economic optimization of conjunctive of surface and groundwater at the basin scale, J. Water Resour. Plan. Manage., 132, 454-467, 2006.
Roderick, M. L.: Introduction to special section on water resources in the Murray-Darling Basin: Past, present, and future, Water Resour. Res., 47, W00G01, doi:10.1029/2011WR010991, 2011.

Röckstrom, J., Steffen, W., Noone, K., Persson, Å., Chapin III, F. S., Lambin, E., Lenton, T. M., Scheffer, M., Folke, C., Schellnhuber, H., Nykvist, B., De Wit, C. A., Hughes, T., van der Leeuw, S., Rodhe, H., Sörlin, S., Snyder, P. K., Costanza, R., Svedin, U., Falkenmark, M., Karlberg, L., Corell, R. W., Fabry, V. J., Hansen, J., Walker, B., Liverman, D., Richardson, K., Crutzen, P., and Foley, J.: Planetary boundaries: Exploring the safe operating space for humanity:. Planetary boundaries:exploring the safe operating space for humanity, Ecol. Soc., 14, 32, available at: http://www.ecologyandsociety.org/vol14/iss2/art32/ (last access: September 2014), 2009.

Romer, P.: Endogenous technological change, Part 2: The problem of development: a conference of the Institute for the Study of Free Enterprise Systems (October 1990), J. Polit. Econ., 98, S71S102, 1990.

Rosero, E., Yang, Z. L., Wagener, T., Gulden, L. E., Yatheendradas, S., and Niu, G. Y.: Quantifying parameter sensitivity, interaction, and transferability in hydrologically enhanced versions of the Noah land surface model over transition zones during the warm season, J. Geophys. Res.-Atmos., (1984-2012), 115, D03106, doi:10.1029/2009JD012035, 2010.

Savenije, H. H. G.: Equifinality, a blessing in disguise?, Hydrol. Process., 15, 2835-2838, 2001.

Savenije, H. H. G., Hoekstra, A. Y., and van der Zaag, P.: Evolving water science in the Anthropocene, Hydrol. Earth Syst. Sci., 18, 319-332, doi:10.5194/hess-18-319-2014, 2014.

Sivapalan, M.: Predictions under Change:Water, Earth and Biota in the Anthropocene. White Paper produced for NSF, available at: http://cwaces.geog.uiuc.edu/synthesis/reports/index.html (last access September 2014), 2011.

Sivapalan, M., Zhang, L., Vertessy, R., and Blöschl, G.: Downward approach to hydrological prediction, Hydrol. Process., 17, 2099. doi:10.1002/hyp.1426, 2003.

Sivapalan, M., Savenije, H. H. G., and Blöschl, G.: Sociohydrology: A new science of people and water, Hydrol. Process., 26, 1270-1276, doi:10.1002/hyp.8426, 2012.

Sivapalan, M., Konar, M., Srinivasan, V., Chhatre, A., Wutich, A., Scott, C. A., Wescoat, J. L. and RodriguezIturbe, I.: Socio-hydrology: Use-inspired water sustainability science for the Anthropocene, Earth's Future, 2, 225-230, doi:10.1002/2013EF000164, 2014.

Sobol, I. M.: Sensitivity analysis for nonlinear mathematical models, Math. Modell. Comput. Exp., 1, 407-414, 1993.

Sobol, I. M.: Global sensitivity indices for nonlinear mathematical models and their Monte Carlo estimates, Math. Comput. Simul., 55, 271-280, 2001.

Song, X., Bryan, B. A., Paul, K. I., and Zhao, G.: Variance-based sensitivity analysis of a forest growth model, Ecol. Modell., 247, 135-143, 2012.

Srinivasan, V.: Coevolution of water security in a developing city, Hydrol. Earth Syst. Sci. Discuss., 10, 13265-13291, doi:10.5194/hessd-10-13265-2013, 2013.

Tang, Y., Reed, P., Wagener, T., and van Werkhoven, K.: Comparing sensitivity analysis methods to advance lumped watershed model identification and evaluation, Hydrol. Earth Syst. Sci., 11, 793817, doi:10.5194/hess-11-793-2007, 2007. 
Turner, G. M.: A Comparison of the Limits to Growth with Thirty Years of Reality, Socio-Economics and the Environment, in: Discussion (SEED) Working Paper Series 2008-09, CSIRO Sustainable Ecosystems, edited by: Splash, C., Canberra, Australia, 2008.

UNEP: United Nations Environmental Program: State-and-Trends of the Environment: 1987-2007, in: Fourth Global Environment Outlook: Environment for Development Assessment Report, edited by: Schomaker, M., Keating, M., and Chenje, M., Progress Press, Malta, ISBN 978-92-807-2872-9, 2007.

Vitousek, P. M., Aber, J. D., Howarth, R. W., Likens, G. E., Matson, P. A., Schindler, D. W., Schlesinger, W. H., and Tilman, D. G.: Human alteration of the global nitrogen cycle: Sources and consequences, Ecol. Appl., 7, 737-750, 1997.

Vörösmarty, C. J., Green, P., Salisbury, J., and Lammers, R. B.: Global water resources: Vulnerability from climate change and population growth, Science, 289, 284-288, doi:10.1126/science.289.5477.284, 2000.
Vörösmarty, C. J., McIntyre, P. B., Gessner, M. O., Dudgeon, D., Prusevich, A., Green, P., Glidden, S., Bunn, S. E., Sullivan, C. A., Reidy Liermann, C., and Davies, P. M.: Global threats to human water security and river biodiversity, Nature, 467, 555-561, 2010.

Wagener, T., Sivapalan, M., Troch, P. A., McGlynn, B. L., Harman, C. J., Gupta, H. V., Kumar, P., Rao, P. S. C., Basu, N. B., and Wilson, J. S.: The future of hydrology: An evolving science for a changing world, Water Resour. Res., 46, W05301, doi:10.1029/2009WR008906, 2010.

World Bank: Global Economic Monitor (GEM) Commodities: available at: http://database.worldbank.org, last access: July 2013.

Zalasiewicz, J., Williams, M., Steffen, W., and Crutzen, P.: The new world of the Anthropocene, Environ. Sci. Technol., 44, 22282231, 2010.

Zehe, E. and Sivapalan, M.: Threshold behaviour in hydrological systems as (human) geo-ecosystems: manifestations, controls, implications, Hydrol. Earth Syst. Sci., 13, 1273-1297, doi:10.5194/hess-13-1273-2009, 2009. 